\author{
Aus dem Fachbereich Medizin \\ der Johann Wolfgang Goethe-Universität \\ Frankfurt am Main \\ betreut am \\ Zentrum für Molekulare Medizin \\ Institut für Kardiovaskuläre Regeneration \\ Direktor/in: Prof. Dr. Stefanie Dimmeler
}

\title{
Evaluierung immunmodulatorischer microRNAs im Rahmen von Immunoseneszenz und chronischer Herzinsuffizienz
}

\author{
Dissertation \\ zur Erlangung des Doktorgrades der Medizin \\ des Fachbereichs Medizin \\ der Johann Wolfgang Goethe-Universität \\ Frankfurt am Main
}

\author{
vorgelegt von \\ Fatima Bach \\ aus Lahore (Pakistan)
}

Frankfurt am Main, 2021 


\author{
Aus dem Fachbereich Medizin \\ der Johann Wolfgang Goethe-Universität \\ Frankfurt am Main \\ betreut am \\ Zentrum für Molekulare Medizin \\ Institut für Kardiovaskuläre Regeneration \\ Direktor/in: Prof. Dr. Stefanie Dimmeler
}

\title{
Evaluierung immunmodulatorischer microRNAs im Rahmen von Immunoseneszenz und chronischer Herzinsuffizienz
}

\author{
Dissertation \\ zur Erlangung des Doktorgrades der Medizin \\ des Fachbereichs Medizin \\ der Johann Wolfgang Goethe-Universität \\ Frankfurt am Main
}

\author{
vorgelegt von \\ Fatima Bach \\ aus Lahore (Pakistan)
}

Frankfurt am Main, 2021 
Dekan:

Referent/in:

Korreferent/in:

Tag der mündlichen Prüfung: $\quad$ 28.05.2021
Prof. Dr. Stefan Zeuzem

Prof. Dr. Stefanie Dimmeler

Prof. Dr. Eike Nagel 
Meiner Mutter gewidmet. 


\section{Danksagung}

Mein besonderer Dank gilt Frau Prof. Dr. Stefanie Dimmeler für die Bereitstellung des interessanten Themas und den ausgezeichneten Arbeitsbedingungen. Frau Prof. Dimmeler ist mit Ihrer Begeisterung und Ihrem Enthusiasmus stets ein Vorbild für mich gewesen.

Herrn Prof. Dr. Andreas Zeiher danke ich für die Bereitstellung der Räumlichkeiten der Medizinischen Klinik I.

Herrn Dr. Timon Seeger danke ich für seine Ausdauer, die er zu jeder Zeit mit mir hatte. Außerdem danke ich inm für die Hilfestellung bei der Erstellung der Statistik.

Frau Sybille Wehner und Frau Olga Zimmermann danke ich für die hervorragende Durchführung in der Flowzytometrie Analyse.

Meinem Mann Christian danke ich für seine Unterstützung und seinen Rückhalt in sämtlichen Lebenslagen, nicht zu vergessen für seine Geduld, die er mir stets entgegenbringt. Sein unermüdlicher Glaube an mich bedeutet mir sehr viel.

Mein besonderer Dank gilt meiner Mutter für ihre grenzenlose Liebe und Unterstützung. Ohne sie wäre ich nicht dort angekommen, wo ich hier und heute stehe. 
Inhaltsverzeichnis

Abbildungsverzeichnis

Tabellenverzeichnis

Abkürzungsverzeichnis __ 9

1. Einleitung _ 12

1.1. Immunoseneszenz __ 12

1.2. Herzinsuffizienz

1.2.1. Epidemiologie __ 18

1.2.2. Herzinsuffizienz und Veränderungen des Immunsystems ___ 19

1.3. MicroRNAs _ 22

1.3.1. Zur Geschichte der microRNas __ 22

1.3.2. Biogenese und Funktion der microRNAs __ 22

1.3.3. MicroRNAs in der Hämatopoese und im Immunsystem ___ 24

1.3.4. MicroRNAs im Prozess der Alterung __ 25

1.4. Zielsetzung der Arbeit___ 26

2. Material und Methoden___ 27

2.1. Studiendesign und Patientengut___ 27

2.1.1. Einschlusskriterien __ 28

2.1.2. Ausschlusskriterien _ 29

2.2. Primärmaterial, Probengewinnung ___ 30

2.2.1 Isolation der zellulären microRNAs__ 30

2.2.3. Reverse Transkription___ 31

2.2.4. Quantitative Polymerase-Kettenreaktion (qPCR) __ 32

2.2.5. Auswertung___ 32

2.2.6. Durchflusszytometrische Analyse___ 33 
2.2.7. Statistische Analyse

3. Ergebnisse 35

3.1. Klinische Studiengruppe ___ 35

3.2. Assoziation zwischen Alterung und miR-181-Expression im PB ___ 36

3.3. Assoziation zwischen CHF und miR-181-Expression im PB __ 36

3.4. Korrelation zwischen Alterung sowie CHF und anderen immunmodulatorischen microRNAs im $\mathrm{PB}$ 37

3.5. Untersuchung von Leukozyten und ihrer Subpopulationen im PB 38

3.5.1. Alters- und CHF-bedingt Änderungen in B-Zellen und deren Subpopulationen 40

3.5.2. Alters- und Herzinsuffizienz-bedingte Änderungen in T-Lymphozyten und _ deren Subpopulationen

3.5.3. Alters- und CHF-bedingte Änderungen in NK-Zellen 42

3.6. Verteilung der Leukozyten-Subpopulationen in Abhängigkeit der CHF Ätiologie 43

3.7. Zelltyp-spezifische Expression der miR-181 Mitglieder in humanem PB _45

3.8. Korrelationsanalysen der Expression von miR-181 Transkripten im PB _46

3.9. Korrelation anderer immunmodulatorischer microRNAs in Leukozyten bzw. deren Subpopulationen 47

3.10. Assoziation zwischen CHF und miRNA-Levels und Immunzellen 48

4. Diskussion 49

4.1. Limitationen der Studie 54

4.2. Schlussfolgerungen für die Zukunft 54

Zusammenfassung 55

Abstract 57

Literaturverzeichnis 59 


\section{Abbildungsverzeichnis}

Abbildung 1: Vereinfachtes Schema der Differenzierung von hämatopoietischen Stammzellen 13

Abbildung 2: Ätiologie der Herzinsuffizienz _ 17

Abbildung 3: Prävalenz und Inzidenz der chronischen Herzinsuffizienz ___ 18

Abbildung 4: Hypothesen zu Ursachen der Immunaktivierung bei $\mathrm{CHF} \_21$

Abbildung 5: Biogenese und Funktion der microRNAs __ 23

Abbildung 6: Studiendesign und Patientengut___ 28

Abbildung 7: Expression der miR-181 Transkripte im PB __ 37

Abbildung 8: Expression weiterer immunmodulatorischer miRNAs im PB _ 38

Abbildung 9: Verteilung der Leukozytensubtypen im PB ___ 39

Abbildung 10: Repräsentativer Blot der Durchflusszytometrie mit Verteilung der Lymphozyten innerhalb der Leukozyten 40

Abbildung 11: B-Zell-Subpopulationen im PB _ 41

Abbildung 12: T-Lymphozyten-Populationen im PB __ 42

Abbildung 13: Fraktion der NK-Zellen im PB _ 42

Abbildung 14: Fraktionen der B-Zellen in Abhängigkeit der Ätiologie bei CHF_43

Abbildung 15: Anteile der Leukozyten-Subpopulationen im PB in Abhängigkeit der CHF Ätiologie

Abbildung 16: Expressionslevels der miR-181 Mitglieder in unterschiedlichen Zellfraktionen in humanem PB

Abbildung 17: hypothetischer Mechanismus, der den Effekt der Alterung und / oder CHF auf das Immunsystem beschreibt 


\section{Tabellenverzeichnis}

Tabelle 1: Charakteristika der Studienkohorte

Tabelle 2: Korrelationskoeffizienten von miR-181 Expressionslevels in Leukozyten bzw. deren Subpopulationen im PB 46

Tabelle 3: Korrelationskoeffizienten von Expressionslevels immunmodulatorischer microRNAs in Leukozyten-Subpopulationen im PB 

Abkürzungsverzeichnis
ACE
Angiotensin-converting-enzyme
ANOVA
analysis of variance
ARB
Angiotensinrezeptorblocker
aHT
arterielle Hypertonie
BMC
mononukleäre Knochenmarkszellen
bzw.
beziehungsweise
C
Celsius
C. elegans
Caenorhabditis elegans
CA
Kalifornien
ca.
circa
CD
Cluster of differentiation
cDNA
komplementäre DNA
$\mathrm{CHF}$
chronische Herzinsuffizienz bzw. chronic heart failure
CLP
lymphoider Vorläufer
CMP
myeloischer Vorläufer
CRP
C-reaktives Protein
DCM
dilatative Kardiomyopathie
DE
Deutschland
dl
Deziliter
DM II
Diabetes mellitus Typ II
DNA
Desoxyribonukleinsäure
dNTP
Desoxyribonukleosidtriphosphate
ECD
Phycoerythrin-Texas Red
EDTA
Ehtylendiamintetraessigsäure
et al
et altera
FACS
Fluroescence-actived cell sorting bzw. Flowzytometrie
FITC
Fluorescein isothiocyanate
g
$\mathrm{g}$ force oder Gramm
GMP
granulozytär-monozytärer Vorläufer
HSC
Hämatopoetische Stammzellen 


\begin{tabular}{|c|c|}
\hline ICM & ischämische Kardiomyopathie \\
\hline $\lg$ & Immunglobuline \\
\hline IL & Interleukin \\
\hline j & ja \\
\hline $\mathrm{kg}$ & Kilogramm \\
\hline KHK & Koronare Herzkrankheit \\
\hline klin. & klinisch \\
\hline I & Liter \\
\hline LT-HSC & long-term reconstituting hämatopoietische Stammzelle \\
\hline LVEF & linksventrikuläre Ejektionsfraktion \\
\hline $\mathrm{mg}$ & Milligramm \\
\hline $\mathrm{ml}$ & Milliliter \\
\hline $\min$ & Minute \\
\hline $\operatorname{miR}(s)$ & microRNA(s) \\
\hline $\operatorname{miRNA}(\mathrm{s})$ & microRNA(s) \\
\hline MRE & microRNA-recognition elements \\
\hline mRNA & messenger RNA \\
\hline MEP & megakaryozytär-erythroider Vorläufer \\
\hline MPP & multipotente Progenitorzelle \\
\hline$\mu \mathrm{g}$ & Mikrogramm \\
\hline$\mu \mathrm{l}$ & Mikroliter \\
\hline $\mathrm{n}$ & nein \\
\hline $\mathrm{nb}$ & nicht bekannt \\
\hline ng & Nanogramm \\
\hline NK & natürliche Killerzellen \\
\hline $\mathrm{nm}$ & Nanometer \\
\hline NT-proBNP & $\mathrm{N}$-terminal pro brain natriuretic-peptide \\
\hline NYHA & New York Heart Association \\
\hline $\mathrm{o} / \mathrm{h}$ & gealterte, gesunde Probanden \\
\hline PB & peripher venöses Blut bzw. peripheral venous blood \\
\hline PCR & Polymerase-Kettenreaktion \\
\hline
\end{tabular}




$\begin{array}{ll}\text { PE } & \text { Phycoerythrin } \\ \text { pg } & \text { Picogramm } \\ \text { pre-microRNA } & \text { precursor microRNA } \\ \text { pri-microRNA } & \text { primäre microRNA } \\ \text { qPCR } & \text { quantitative Polymerase-Kettenreaktion } \\ \text { RISC } & \text { RNA-induced silencing complex } \\ \text { RNA } & \text { Ribonukleinsäure } \\ \text { RNase } & \text { Ribonuklease } \\ \text { RT-PCR } & \text { Reverse Transkription Polymerase-Kettenreaktion bzw. } \\ & \text { reverse transcription polymerase chain reaction } \\ \text { sec } & \text { Sekunde } \\ \text { ST-HSC } & \text { short-term reconstituting hämatopoetische Stammzelle } \\ \text { stRNA } & \text { small temporal RNA } \\ \text { TNF } & \text { Tumornekrosefaktor } \\ \text { UTR } & \text { untranslatierte Region } \\ \text { WHO } & \text { World Health Organization } \\ \text { y/h } & \text { junge, gesunde Probanden } \\ \text { zytotox. } & \text { zytotoxisch }\end{array}$




\section{Einleitung}

\subsection{Immunoseneszenz}

Immunoseneszenz beschreibt die altersbedingte Abnahme spezifischer Funktionen des Immunsystems sowie die zugrundeliegenden Mechanismen und wurde initial 1969 vom Gerontologen Roy Walford geprägt. ${ }^{1}$

Die Immunoseneszenz ist charakterisiert durch eine Abnahme der zellvermittelten Immunfunktion sowie durch eine reduzierte humorale Immunantwort. ${ }^{2}$ Zugrunde liegen komplexe Prozesse, welche zu einer Umstrukturierung und zu qualitativen Veränderungen einzelner Funktionen des Immunsystems führt. ${ }^{3}$ Alle Organe und Zellen des angeborenen und erworbenen Immunsystems, einschließlich der hämatopoietischen Stammzellen (HSC), der lymphoiden Vorläuferzellen in Knochenmark und Thymus, der reifen T- und B-Lymphozyten in den sekundären Lymphorganen wie auch Zellen des angeborenen Immunsystems sind daran beteiligt. ${ }^{4}$ Im Vergleich zum angeborenen Immunsystems ist das erworbene Immunsystem vom Prozess der Immunoseneszenz in größerem Ausmaß betroffen. ${ }^{5}$

Stammzellen haben die Eigenschaft, sich selbst zu erneuern - „self-renewal“ - und sich zu differenzieren. ${ }^{6}$ Die Differenzierung und Hämostase des hämatopoietischen Systems unterliegt einer exakten Regulierung. Während der embryonalen Entwicklung findet die Hämatopoese zuerst im Dottersack, dann in der Plazenta, anschließend in der fetalen Leber und zuletzt im Knochenmark statt. ${ }^{7}$ Stammzellen

1 Walford RL. The immunologic theory of aging. Gerontologist. 1969;4:195-7.

2 Weisskopf D, Weinberger B, Grubeck-Loebenstein B. The aging of the immune system. Transpl Int. 2009;22:1041-50.

3 Globerson A, Effros RB. Ageing of lymphocytes and lymphocytes in the aged. Immunol Today. 2000;10:515-21.

4 Plackett TP, Boehmer ED, Faunce DE, Kovacs EJ. Aging and innate immune cells. J Leukoc Biol. 2004;76:291-9.

5 Franceschi $\mathrm{C}$, Bonafe $\mathrm{M}$, Valensin S. Human immunosenescence: the prevailing of innate immunity, the failing of clonotypic immunity, and the filling of immunological space. Vaccine. 2000; 18:1717-20.

6 Seita J, Weissman IL. Hematopoietic Stem Cell: self-renewal versus differentiation. Wiley Interdiscip Rev Syst Biol. Med. 2010;2(6):640-53.

7 Orkin SH, Zon LI: Hematopoiesis: an evolving paradigm for stem cell biology. Cell. 2008;132(4):631-44. 
im adulten Knochenmark können verschiedene Subtypen unterteilt werden: die pluripotenten long-term reconstituting HSCs (LT-HSC) und short-term reconstituting HSCs (ST-HSC). Diese pluripotenten Stammzellen haben die Möglichkeit, sich zu multipotenten Progenitorzellen (MPP) zu differenzieren. Hieraus differenzieren sich oligopotente Progenitorzellen, lymphoide (CLP), myeloide (CMP), megakaryozytärerythroide (MEP) und granulozytär-monozytäre (GMP) Vorläuferzellen. Aus diesen entwickeln sich schließlich die terminal differenzierten B-, $T$ und NatürlicheKiller(NK)-Zellen sowie Granulozyten, Monozyten/Makrophagen, Mastzellen und Megakaryozyten weiter (Abbildung 1).

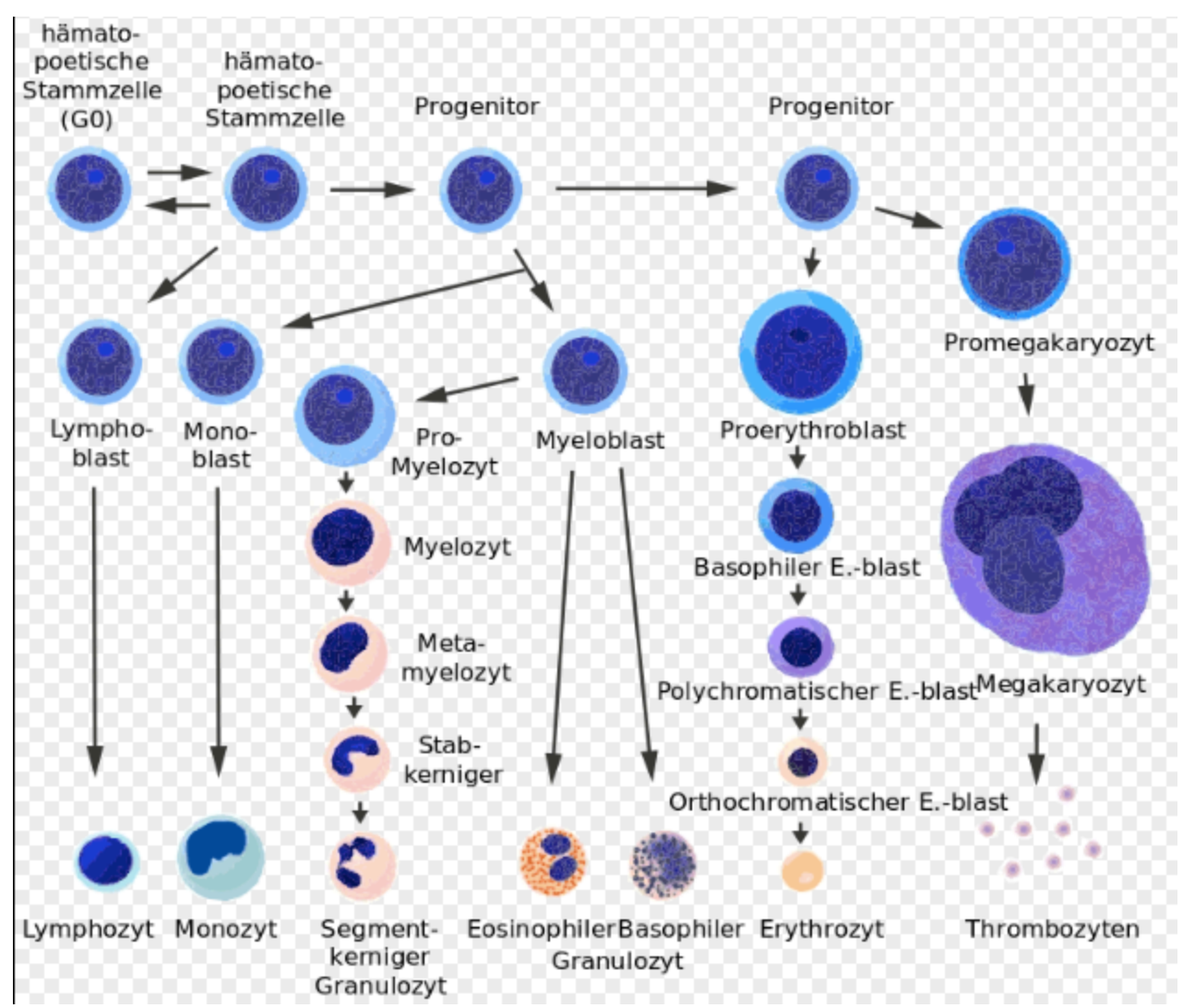

Abbildung 1: Vereinfachtes Schema der Differenzierung von hämatopoietischen Stammzellen ${ }^{8}$ aus Blood_cells_differentiation_chart.jpg: パタゴニア derivative work: Furfur (talk) Blood_cells_differentiation_chart.jpg, CC BY-SA 3.0, https://commons. wikiedia.org/w/index.php?curid=15411966

8 Wikipedia. https://commpns. wikiedia.org/w/index.php?curid=15411966. Mai, 05, 2020. 
Die zellulären Anteile des Immunsystems unterliegen überwiegend einer kontinuierlichen Erneuerung, ausgehend von HSC, aus denen sich mit zunehmender Differenzierung über unterschiedliche Vorläuferzellen die jeweiligen Leukozyten-Subpopulationen herausbilden (siehe Abbildung 1). Jedes Entwicklungsstadium ist durch die Expression charakteristischer Oberflächenantigene charakterisiert. Diese Oberflächenantigene gehören größtenteils der Familie der cluster of differentiation-Moleküle (CD-Moleküle) an. Cluster of differentiation bezeichnet eine Gruppe immunphänotypischer Oberflächenmerkmale, meist handelt es sich um Glykoproteine, die teilweise zellspezifisch exprimiert werden. ${ }^{9}$

Mit zunehmendem Alter kommt es zu einer spezifischen Reduktion der Erneuerungskapazität für HSC. Gealterte HSC zeigen eine reduzierte Differenzierung in Richtung lymphoider Zellen, sie verlieren ihr Potenzial T- und BLymphozyten effizient zu generieren, ${ }^{10}$ sodass es zu einer Verschiebung in Richtung myeloischer Zellreihen kommt. ${ }^{11}$

Diese Verschiebung betrifft insbesondere die B-Zelllinie, es tritt eine altersabhängig signifikante Reduktion von B-Lymphozyten im peripheren Blut auf. ${ }^{12}$ Dabei sind die Änderungen für die spezifischen Subtypen unterschiedlich stark ausgeprägt. So führen altersassoziierte Veränderungen zu reduzierten Zahlen an zirkulierenden

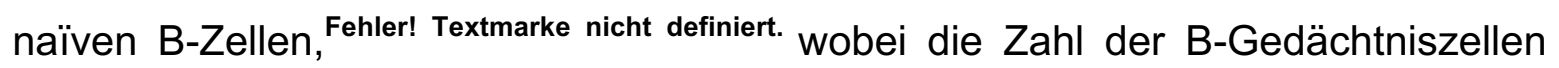
erhöht ist. ${ }^{13}$ Darüber hinaus beobachtete man im Rahmen von Immunoseneszenz

9 Mason D, André P, Bensussan A. CD antigens 2002. Blood. 2002;15;99:3877-80.

10 Linton PJ, Dorshkind K. Age-related changes in lymphocyte development and function. Nat Immunol. 2004;5:133-39.

11 Geiger H, Rudolph KL. Aging in the lympho-hematopoietic stem cell compartment. Trends Immunol. 2009;30:360-5.

12 Johnson KM, Owen K, Witte PL. Aging and developmental transitions in the B cell lineage. Int Immunol. 2002;14(11):1313-23.

13 Peters T. Immunosenescence. Current status and molecular mechanisms. Hautarzt. 2011; 62(8):598-606. 
bei B-Gedächtniszellen eine beeinträchtigte Fähigkeit sich zu Plasma-Zellen zu differenzieren. ${ }^{14}$

Neben den spezifischen altersbedingten Veränderungen in der Zahl und Zusammensetzung der B-Lymphozyten sind auch Subpopulationen von TLymphozyten im Rahmen von Immunoseneszenz betroffen. Obwohl im Laufe des Lebens die Zahl an totalen T-Lymphozyten überwiegend konstant bleibt, kommt es im Laufe der Alterungsprozesses zu einem Verlust der naïven T-Zellen, also TZellen ohne Antigenkontakt, während die Zahl der CD28- T-Gedächtniszellen ansteigt. ${ }^{15-16}$ Weiterhin gibt es Hinweise, dass trotz steigender Zahl an zirkulierenden CD28- T-Gedächtniszellen ihre Funktion durch den Alterungsprozesses beeinträchtigt ist. ${ }^{17}$

Insgesamt führen die Veränderungen des Immunsystems im Rahmen von Immunoseneszenz zu einer erhöhten Anfälligkeit älterer Menschen für infektiöse Erkrankungen und möglicherweise auch für Autoimmunerkrankungen und Krebskrankheiten sowie ein vermindertes Ansprechen auf Impfungen. ${ }^{18-20}$

Die stetig steigende Lebenserwartung und der daraus resultierende hohe Anteil an älteren Menschen stellen den klinischen Altag vor neue Herausforderungen. Vor diesem Hintergrund ist das Verständnis der Immunoseneszenz von erheblichem Interesse.

14 Matteo B, Calogero C, Giuseppina CR. From lymphopoiesis to plasma cells differentiation, the age-related modifications of B cell compartment are influenced by „inflamm-ageing“. Ageing Res Rev. 2017;36:125-36.

15 Wenjuan T, Sudha R. Mechanisms underlying $T$ cell immunosenescence: aging and Cytomegalovirus infection. Front Microbiol. 2016;7:2111.

16 Fukushima $\mathrm{Y}$, Minato N, Massakazu H. The impact of senescence-associated $\mathrm{T}$ cells on immunosenescence and age-related disorders. Inflamm Regen. 2018;38:24.

17 Miller RA. The aging immune system: primer and prospectus. Science. 1996;273:70-4.

18 Pawelec G, Solana R, Remarque E, Mariani E. Impact of aging on innate immunity. J Leukoc Biol. 1998;64:703-12.

19 Pawelec G. Immunosenescence: impact in the young as well as in the old? Mech Ageing Dev. 1999;108:1-7.

20 Ademokun A, Wu YC, Dunn-Walters D. The ageing B cell population: composition and function. Biogerontology. 2010;11:125-37. 


\subsection{Herzinsuffizienz}

Herzkreislauferkrankungen tragen einen erheblichen Anteil zur Morbidität und Mortalität in den Industrienationen bei. Sie stellen mit über $40 \%$ die häufigste Todesursache bei Menschen über 65 Jahren dar, ${ }^{21}$ und zunehmendes Alter ist einer der signifikanten Einflussgrößen für kardiovaskuläre Erkrankungen. ${ }^{22}$

Eine häufige Endstrecke der unterschiedlichen Erkrankungen ist die Herzinsuffizienz. Die Herzinsuffizienz wird nach der World Health Organization (WHO) über eine verminderte körperliche Belastbarkeit aufgrund einer ventrikulären Funktionsstörung definiert. In einem Teil der Fälle sind direkt, primär oder sekundär, die Kardiomyozyten betroffen, so dass man von Kardiomyopathien spricht. Zumeist führen jedoch auch Ursachen das gesamte kardiale Gewebe betreffend zu Herzinsuffizienz. So ist die Hauptursache der Herzinsuffizienz in den Industriestaaten mit etwa $60 \%$ die koronare Herzkrankheit (KHK) ${ }^{23}$ Herzinsuffizienz aufgrund von vaskulären Ereignissen wird häufig auch als ischämische Kardiomyopathie bezeichnet (ICM) (Abbildung 2). Daneben besteht in einem weiteren großen Teil der Fälle eine dilatative Kardiomyopathie (DCM). ${ }^{24}$ Die Ursachen der dilatativen Kardiomyopathie sind heterogen, sie können unterteilt werden in genetische oder nichtgenetische Ursachen. So können neben genetischen Mutationen auch chronische Inflammationsreaktionen des Myokards, Toxine oder Autoimmunerkrankungen zur Dilatativen Kardiomyopathie führen. ${ }^{25-26}$

21 Lakatta EG. Age-associated cardiovascular changes in health: impact on cardiovascular disease in older persons. Heart Fail Rev. 2002;7(1):29-49.

22 North BJ, Sinclair DA. The intersection between aging and cardiovascular disease. Circ Res. 2012;110:1097-108.

23 Fox KF, Cowie MR, Wood DA, et al. Coronary artery disease as the cause of incident heart failure in the population. Eur Heart J. 2001;22(3):228-35.

24 Dickstein K, Cohen-Solal A, Filippatos G, et al. ESC Guidelines for the diagnosis and treatment of acute and chronic heart failure 2008: The task force for the diagnosis and treatment of acute and chronic heart failure 2008 of the European Society of Cardiology. developed in collaboration with the Heart Failure Association of the ESC (HFA) and endorsed by the European Society of Intensive Care Medicine (ESICM). Eur Heart J. 2008;29(19):2388-442.

25 Schultheiss HP, Fairweather D, Caforio ALP, et al. Dilated cardiomyopathy. Nat Rev Dis Primers. 2019;9;5(1):32.

26 Reichart D, Magnussen C, Zeller T, Blankenberg S. Dilated cardiomyopathy: from epidemiologic to genetic phenotypes. J Int Med. 2019;286/4:362-72. 


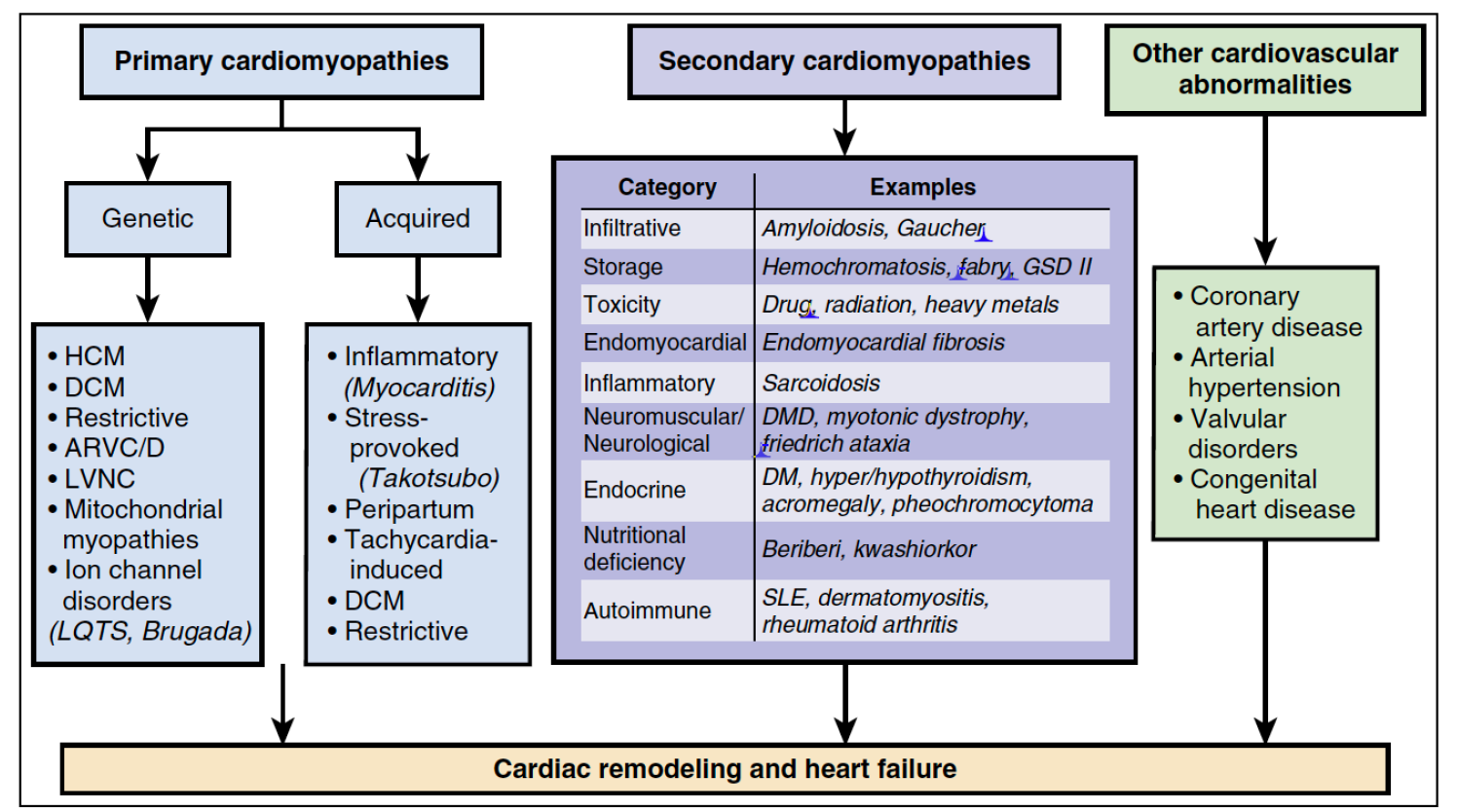

Abbildung 2: Ätiologie der Herzinsuffizienz ${ }^{27}$

aus Seeger T, Chen C, Karakikes I, Wu Jc. Cardiac remodeling and regeneration. Cardiac Electrophysiology: From Cell to Bedside. 7th ed., 2018.

Zumeist besteht eine Linksherz-Insuffizienz, es kommt jedoch auch zum Auftreten von isolierter Rechtsherzinsuffizienz sowie von einer Globalinsuffizienz. Daneben wird die Herzinsuffizienz nach ihrem zeitlichen Verlauf als akut oder chronisch eingeteilt.

Klinische Zeichen einer CHF sind unter anderem Abgeschlagenheit, Dyspnoe sowie verminderte Leistungsfähigkeit. ${ }^{28}$. Die klinische Beurteilung erfolgt nach der NYHAKlassifikation (New York Heart Association). Während die NYHA-Stadien I-III eine Herzerkrankung ohne bzw. mit leichter oder schwerer Einschränkung der Leistungsfähigkeit unter Belastung beschreiben, treten im Stadium IV die Beschwerden auch schon in Ruhe auf. Um die Diagnose der Herzinsuffizienz stellen zu können, müssen laut der European Society of Cardiology die Symptome - in Ruhe

${ }^{27}$ Seeger T, Chen C, Karakikes I, Wu JC. Cardiac remodeling and regeneration. Cardiac Electrophysiology: From Cell to Bedside. 7th ed., 2018.

28 Erdmann. Klinische Kardiologie. Krankheiten des Herzens, des Kreislaufs und der herznahen Gefäße. 8. überarbeitete Aufl. Springer Verlag, Heidelberg 2011. 
oder unter Belastung - sowie ein objektiver Nachweis einer Dysfunktion - systolisch oder diastolisch - vorliegen. Letztes wird zumeist mittels Echokardiographie ermittelt.

In den letzten Jahren hat sich das Verständnis der Herzinsuffizienz verändert, weg vom vereinfachten Modell des kardialen Pumpversagens hin zu einer Multisystemerkrankung, die nicht nur das kardiovaskuläre System, sondern auch das neuroendokrine, muskuloskelettale und renale System sowie das Immunsystem einschließt. $^{29}$

\subsubsection{Epidemiologie}

Die Prävalenz der CHF beträgt global geschätzt ca. 2-3 $\%,{ }^{30}$ in der westlichen Welt ca. $1-2 \% .{ }^{31}$ Die Epidemiologie ist stark altersabhängig (Abbildung 3).

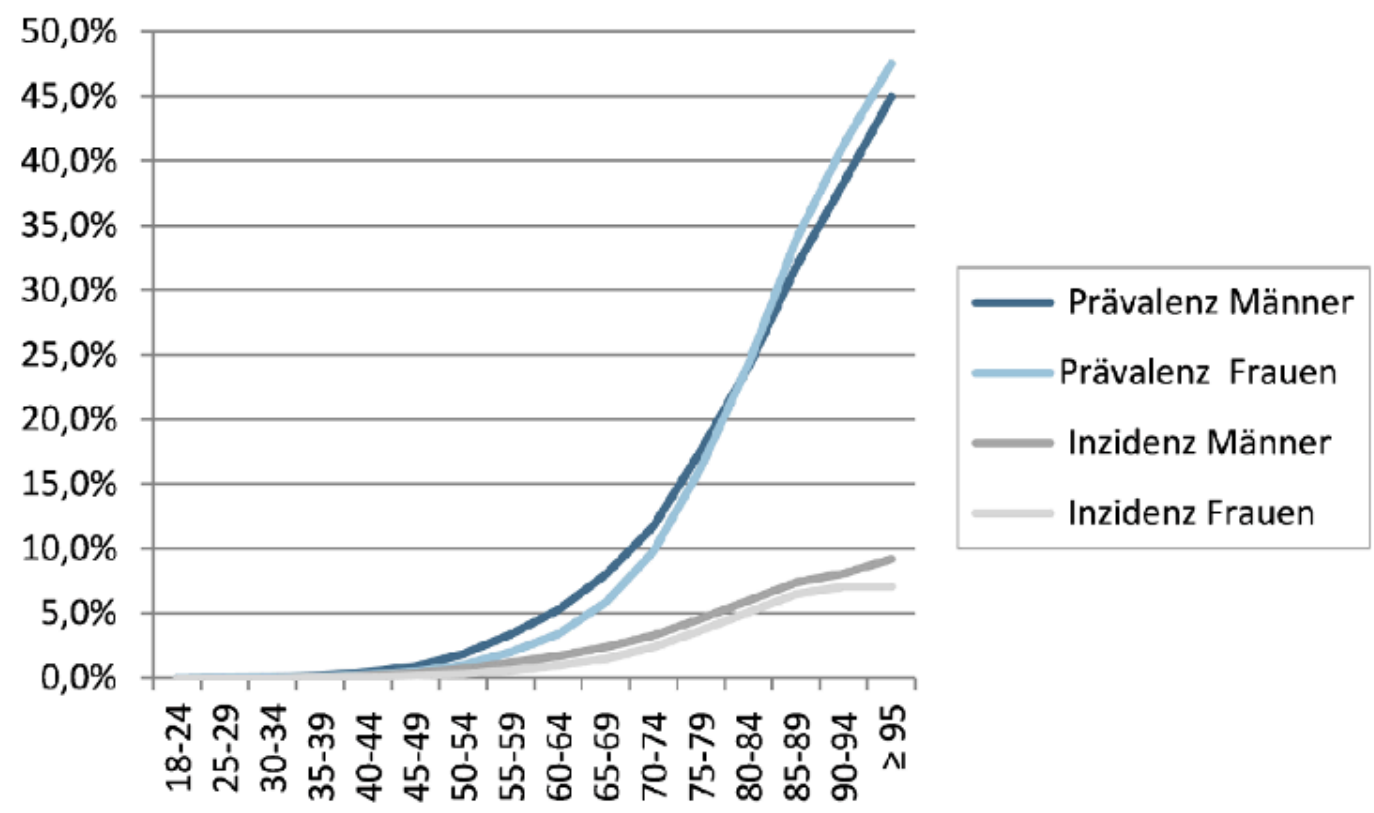

Abbildung 3: Prävalenz und Inzidenz der chronischen Herzinsuffizienz ${ }^{32}$ aus https://www.leitlinien.de/nvl/html/nvl-chronische-herzinsuffizienz/3auflage/kapitel-2

29 Genth-Zotz S, von Haehling S, Blankenberg S. Immunactivation in chronic heart failure: inflammatory mediators. Z Kardiol. 2004;93:24-30.

30 Bui AL, Horwich TB, Fonarow GC. Epidemiology and risk profile of heart failure. Nat Rev Cardiol. 2011;8:30-41.

31 Mosterd A, Hoes AW. Clinical Epidemiology of heart failure. Heart. 2007;93:1137-1146.

32 Leitlinien. https://www.leitlinien.de/nvl/html/nvl-chronische-herzinsuffizienz/3-auflage/kapitel-2. Januar 2019. 
Während die Erkrankung bei Menschen unter 50 Jahren kaum vorkommt, erhöht sich die Prävalenz und Inzidenz mit steigendem Alter, so beträgt die Anzahl der Erkrankungen bei Menschen in der achten Dekade bereits $10 \% .{ }^{33}$ Der deutliche Einfluss des Alters auf die Häufigkeit der CHF wird in der Framingham Studie als „doubling-by-decade“-Effekt bezeichnet. ${ }^{34}$

Während heutzutage die altersbezogene Mortalität für die meisten kardiovaskulären Erkrankungen sinkt, bleibt sie bei der CHF konstant hoch. ${ }^{35}$

\subsubsection{Herzinsuffizienz und Veränderungen des Immunsystems}

Wie bereits obenstehend erwähnt wird CHF heute als Multisystemerkrankung gesehen. In den letzten Jahren konnte in einigen Arbeiten gezeigt werden, dass unter anderem Änderungen des Immunsystems und der Prozess der Immunoseneszenz eine große Rolle im Zuge der CHF spielen. ${ }^{36}$ Anker et al bezeichneten die Krankheit als einen „Zustand der chronischen Inflammation“ mit

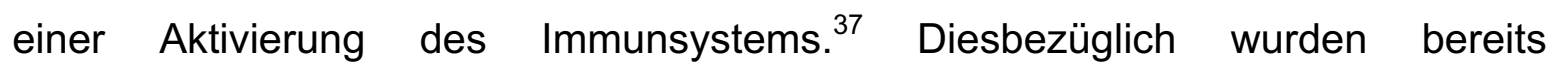
proinflammatorische Zytokine wie Tumornekrosefaktor- $\alpha$ (TNFa) und Interleukin (IL) 1, 2 und 6 als unabhängige Prädiktoren eines schlechteren Überlebens bei CHF beschrieben. ${ }^{38-39}$

33 Herold G. Innere Medizin. Eine vorlesungsorientierte Darstellung. 2018.

34 Kannel WB, Ho K, Thom T. Changing epidemiological features of cardiac failure. Eur Heart $\mathrm{J}$. 1994;72:3-9.

35 Akosah KO, Moncher K, Schaper A, Havlik P, Devine S. Chronic heart failure in the community: missed diagnosis and missed opportunities. J Card Fail. 2001;7:232-8.

36 von Haehling S, Schefold JC, Jankowska E, et al. Leukocyte redistribution: effects of beta blockers in patients with chronic heart failure. PLoS One. 2009;4:e6411.

37 Anker SD, von Haehling S. Inflammatory mediators in chronic heart failure: an overview. Heart. 2004;90:464-70.

38 Rauchhaus M, Doehner W, Francis DP, Davos C, Kemp M, et al. Plasma cytokine parameters and mortality in patients with chronic heart failure. Circulation. 2000;19;102:3060-7.

39 Deswal A, Petersen NJ, Feldman AM, Young JB, White BG, et al. Cytokines and cytokine receptors in advanced heart failure: an analysis of the cytokine database from the Vesnarinone trial (VEST). Circulation. 2001;103:2055-9. 
Die Ursache dieser Immunaktivierung ist noch nicht ausreichend geklärt, hierzu existieren unterschiedliche Hypothesen. ${ }^{40}$ Eine Hypothese geht davon aus, dass es durch ein Ödem in der Darmwand zu einer bakteriellen Translokation kommt, welche anschließend zu einer Endotoxinfreisetzung und Immunaktivierung führt (Abbildung 4). ${ }^{41}$ Hierfür spricht, dass in Patientin mit CHF erhöhte Endotoxinspiegel gemessen wurden. ${ }^{42}$ Eine andere Hypothese sieht das Herz selbst als Hauptquelle für die Zytokine. Dies wird durch die Tatsache unterstützt, dass TNFa lediglich in geschädigtem, aber nicht im gesunden Myokard produziert wird. ${ }^{43}$ Eine weitere Hypothese geht davon aus, dass eine systemische Hypoxie ein potenter Stimulus für die Immunaktivierung und Zytokinproduktion ist (Abbildung 4). ${ }^{44}$

40 Mari, D, Di Berardino, F, Cugno, M. Chronic heart failure and the immune system. Clinic Rev Allerg Immunol. 2002;23:325-40.

${ }^{41}$ Anker SD, Egerer KR, Volk HD, Kox WJ, Poole-Wilson PA, Coats AJ. Elevated soluble CD14 receptors and altered cytokines in chronic heart failure. Am J Cardiol. 1994;49:1426-30.

42 Niebauer J, Volk HD, Kemp M, Dominguez M, et al. Endotoxin and immune activation in chronic heart failure. A prospective cohort study. Lancet. 1999;353:1838-1842.

43 Habib FM, Springall DR, Davies GJ, Oakley CM, Yacoub MH, Polak J. Tumor necrosis factor and inducible nitric oxide synthase in dilated cardiomyopathy. Lancet. 1996;347:1151-5.

44 Scannell G, Waxman K, Kaml GJ,et al. Hypoxia induces a human macrophage cell line to release tumor necrosis factor- $\alpha$ and its soluble receptors in vitro. J Surg Reg. 1993;54:281-5. 


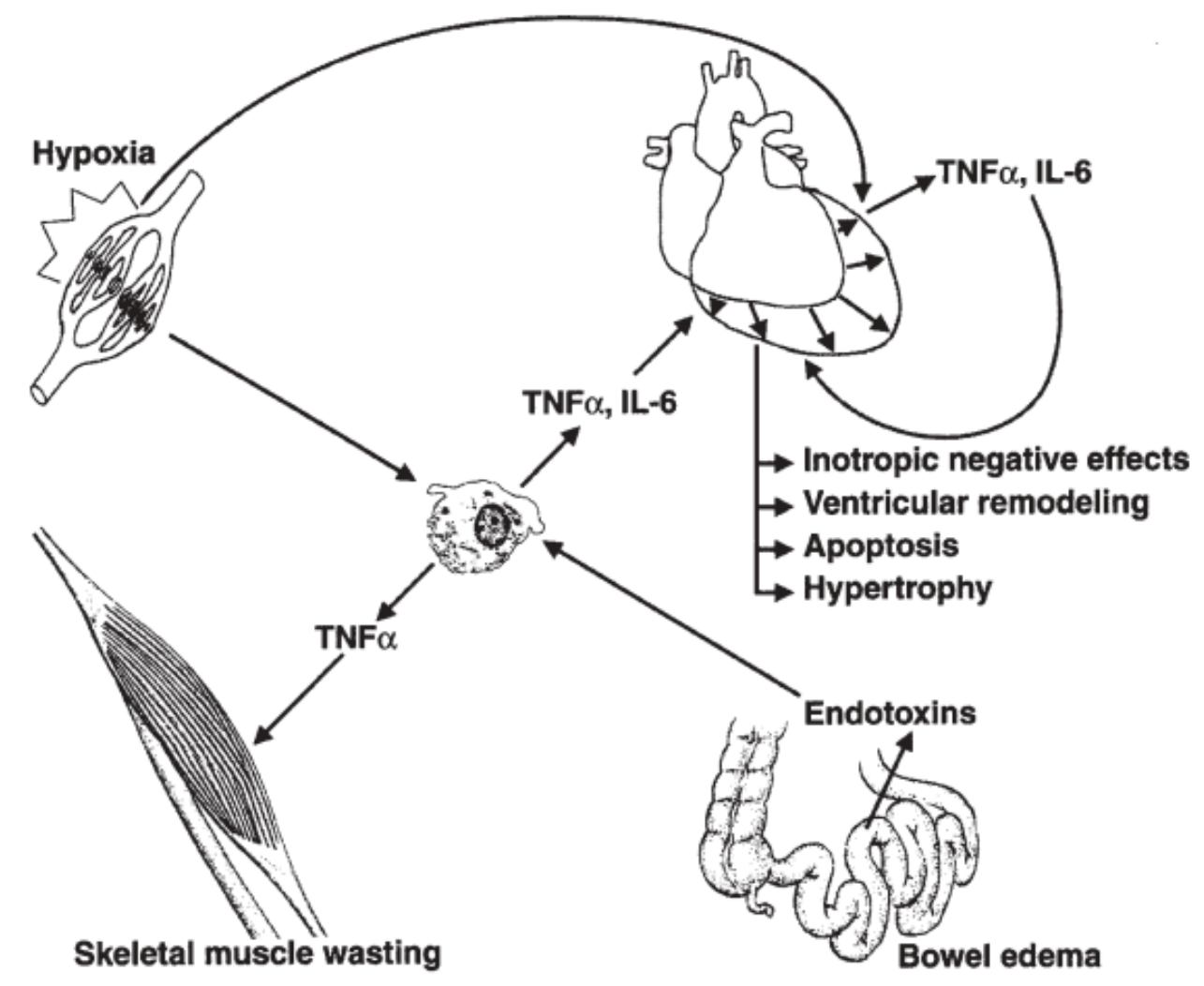

Abbildung 4: Hypothesen zu Ursachen der Immunaktivierung bei $\mathrm{CHF}^{40}$ aus Mari, D, Di Berardino, F, Cugno, M. Chronic heart failure and the immune system. Clinic Rev Allerg Immunol. 2002;23:325-40.

Neben der oben beschriebenen Immunaktivierung wurden weitere Änderungen des Immunsystems beschrieben: Maisel et al konnten zeigen, dass im peripheren Blut (PB) der Patienten mit CHF im Vergleich zu gesunden, altersentsprechenden Kontrollprobanden zu einer Reduktion der Zahl der Lymphozyten sowie zu einer Umverteilung der Leukozyten-Subgruppen kommt. ${ }^{45}$ Weitere Untersuchungen legen nahe, dass jene Lymphozytopenie ein wichtiger negativer Prognosefaktor für Patienten mit akuter und chronischer Herzinsuffizienz ist. ${ }^{46-47}$

Maisel AS, Knowloton KU, Fowler $\mathrm{P}$, et al. Adrenergic control of circulating lymphocyte subpopulations. Effects of congestive heart failure, dynamic exercise, and terbutaline treatment. J Clin Invest. 1990;85:462-7.

46

Nunez J, Nunez E, Minana G, et al. Effectiveness of the relative lymphocyte count to predict oneyear mortality in patients with acute heart failure. Am J Cardiol. 2011;107:1034-9.

47 Acanfora D, Gheorghiade M, Trojano L, et al. Relative lymphocyte count: a prognostic indicator of mortality in elderly patients with congestive heart failure. Am Heart J. 2001;142:167-73. 


\subsection{MicroRNAs}

MicroRNAs (miRNAs) sind kleine, nicht-kodierende, einzelsträngige RNA-Moleküle mit einer Länge von ca. 22-24 Nukleotiden, die an der Regulierung der Expression von Proteinen beteiligt sind. Sie binden gezielt an spezifische Sequenzen einer ZielmessengerRNA und führen so zur Degradation des mRNA-Transkripts oder inhibieren direkt die Protein-Translation. ${ }^{48-49}$ Sie sind als einflussreiche Modulatoren ganzer molekularbiologischer Regelkreise in den letzten Jahren zunehmend in den Fokus gerückt.

\subsubsection{Zur Geschichte der microRNAs}

Im Jahr 1993 wurde von Victor Ambros und seinen Kollegen in Caenorhabditis elegans ein Gen namens lin-4 beschrieben, das nicht für ein Protein kodierte, sondern für zwei kleine RNA-Moleküle mit einer Länge von ca. 22 Nukleotiden. ${ }^{49}$ Diese RNA wurde zunächst als stRNA (small temporal RNA) bezeichnet. Nachdem weitere solcher kleinen RNAs entdeckt wurden, bekamen sie 2001 den Namen microRNAs. ${ }^{50}$ Bis heute (Stand 2020) sind mehrere Tausend solcher humanen microRNAs identifiziert worden und in den offiziellen Datenbanken (z.B. miRBaseDatenbank; http://www.mirbase.org) registriert. Innen wird eine große Bedeutung bei der Kontrolle regulatorischer Mechanismen und bei Krankheitsentstehung im Allgemeinen zugesprochen.

\subsubsection{Biogenese und Funktion der microRNAs}

Die Biogenese von microRNAs durchläuft mehrere Schritte und beginnt im Nucleus (Abbildung 5).

48 Bartel DP. MicroRNAs: target recognition and regulatory functions. Cell. 2009;136(2):215-33.

49 Lee RC, Feinbaum RL, Ambros V. The C. elegans heterochronic gene lin-4 encodes small RNAs with antisense complementarity to lin-14. Cell. 1993;75(5):843-54.

50 Lagos-Quintana M, Rauhut R, Lendeckel W, Tuschl T. Identification of novel genes coding for small expressed RNAs. Science. 2001;294:853-58. 


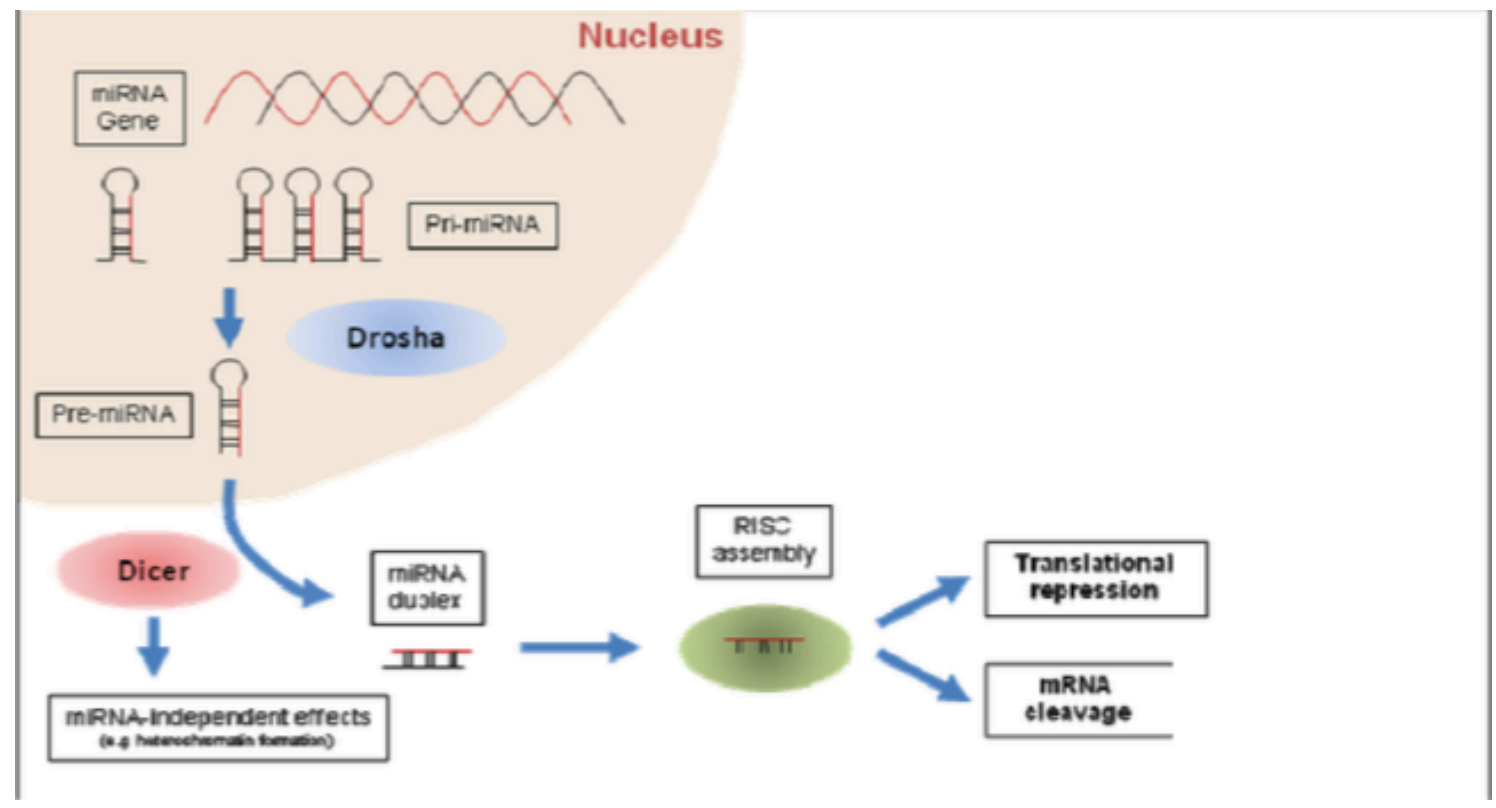

Abbildung 5: Biogenese und Funktion der microRNAs ${ }^{51}$

aus Bonauer A. Die Bedeutung von microRNAs für die Funktion von Endothelzellen [Dissertation]. Johann Wolfgang Goethe-Universität;2008.

Hier wird die primäre microRNA (pri-microRNA) durch die RNA-Polymerase II oder III transkribiert. Die pri-microRNA wird anschließend durch die Ribonuklease (RNase) III (Drosha) zur pre-microRNA (precursor-microRNA) prozessiert. Diese ist ein etwa 60-70 Nukleotid langes RNA-Molekül mit charakteristischer Haarnadelstruktur. ${ }^{52}$ Anschließend wird die pre-microRNA durch Exportin 5 vom Nukleus ins Zytoplasma transportiert. ${ }^{53}$ Die Endonuklease Dicer schneidet dort die pre-microRNA an spezifischen Erkennungssequenzen zu einer ca. 22 Nukleotid langen reifen microRNA. ${ }^{54}$ Die reife miRNA wird in den RISC (RNA-inducedsilencing complex) inkorporiert. ${ }^{55}$ Die in den RISC korporierte microRNA kann dann an bestimmte Erkennungssequenzen (MREs; microRNA-recognition elements)

51 Bonauer A. Die Bedeutung von microRNAs für die Funktion von Endothelzellen [Dissertation].Frankfurt, Johann Wolfgang Goethe-Universität; 2008.

52 Lee Y, Ahn C, Han J, et al. The nuclear RNase III Drosha initiates microRNA processing. Nature. 2003;425:415-9.

53 Lund E, Guttlinger S, Calado A, Dahlberg JE, Kutay U. Nuclear export of microRNA precursors. Science. 2004;303:95-8.

54 Bartel DP. MicroRNAs: genomics, biogenesis, mechanism, and function. Cell. 2004;116:281-97.

55 Hammond SM, Boettcher S, Caudy AA, Kobayashi R, Hannon GJ. Argonaute2, a link between genetic and biochemical analyses of RNA. Science. 2001;293;146-50. 
binden, und inhibiert so die Translation oder induziert durch eine Deadenylierung der mRNA deren Degradation.

MREs spezifisch für eine microRNA sind zumeist in der 3'-untranslationierten Region (UTR) der mRNA eines Zielgens zu finden. Häufig kommen MREs spezifisch für eine microRNA dabei in vielen Ziel-mRNAs vor, so können einzelne microRNAs ganze Signalnetzwerke modulieren und als post-transkriptionales fine-tuning-Instrument von Signalkaskaden fungieren. ${ }^{56}$

\subsubsection{MicroRNAs in der Hämatopoese und im Immunsystem}

Seit der initialen Beschreibung von microRNAs sind verschiedene spezifische microRNAs identifiziert worden, die in der Kontrolle von Prozessen der Differenzierung und Spezifizierung im Rahmen der Hämatopoese sowie von zellulären Immunfunktionen maßgeblich beteiligt. ${ }^{57}$

Die ersten Beschreibungen von miRNA-Beteiligung in der Hämatopoese wurden von Chen et $\mathrm{al}^{58}$ geliefert: Die Arbeitsgruppe konnte zeigen, dass microRNAs in hämatopoietischen Zellen exprimiert werden und ihre Expression während der frühen Hämatopoese einen dynamischen Charakter hat. Die Arbeitsgruppe identifizierte eine spezifische Anreicherung microRNA-181 in der B-Zell-Reihe im Knochenmark von Mäusen. Eine gesteigerte Expression dieser microRNA-181 in HSCs führte zu einer erhöhten Fraktion der B-Zell-Linie, sowohl in Zellkulturen als auch in adulten Mäusen. Weitere miRNAs wurden in unterschiedlichen Stadien der Hämatopoese und in Immunfunktionen beschrieben, insbesondere die miR-34a als negativer Regulator in B-Zell-Reifung, ${ }^{59}$ miR-146a und miR-155 als Regulatoren in

56 Meister G, Tuschl T. Mechanisms of gene silencing by double-stranded RNA. Nature. 2004;431:343-9.

57 Wang LD, Wagers AJ. Dynamic niches in the origination and differentiation of haematopoietic stem cell. Nat Rev Mol Cell Biol. 2011;12(10):643-55.

58 Chen CZ, Li L, Lodish HF, Bartel DP. MicroRNAs modulate hematopoietic lineage differentiation. Science. 2004;303:83-6.

59 Rao DS, O'Connell RM, Chaudhuri AA, Garcia-Flores y, Geiger TL, Baltimore D. MicroRNA-34a pertubs B lymphocyte development by repressing the forkhead box transcription factor Foxp1. Immunity. 2010;33:48-59. 
beiden Zweigen der Hämatopoese (lymphoid und myeloid) ${ }^{60-61}$ und die mehr in der myeloischen Reihe angereicherte miR-223. ${ }^{62}$

\subsubsection{MicroRNAs im Prozess der Alterung}

MicroRNAs wurden auch als bedeutende Regulatoren von Alterungsprozessen identifiziert. So wurde eine zentrale Rolle im Alterungsprozess bereits für die microRNA-34a beschrieben. ${ }^{63-64}$ In Caenorhabditis elegans (C. elegans) führte ein Funktionsverlust des Gens in-4 zu einer signifikant reduzierten Lebensdauer, wohingegen es bei einer Überexpression des Gens zu einer Verlängerung des Überlebens kam. ${ }^{65}$ Noch ist unklar, über welche exakten Mechanismen der Alterungsprozess kontrolliert wird. Mittlerweile wurden jedoch zahlreiche weitere microRNAs identifiziert, welche im Alterungsprozess von $C$. elegans verändert reguliert sind. So ist eine Herunterregulation von let-7 bzw. von miR-1 mit einer verlängerten Lebensdauer verbunden. ${ }^{66-67} \mathrm{Im}$ Alter als hochreguliert beschriebene microRNAs sind miR-71, miR-239 und miR-246. ${ }^{63}$

60 Georgantas RW 3rd, Hildreth R, Morisot S, et al. CD34+ hematopoietic stem-progenitor cell microRNA expression and function: a circuit diagram of differentiation control. Pro Natl Acad Sci U S A. 2007;104:2750-5.

61 Thai TH, Calado DP, Casola S, et al. Regulation of the germinal center response by microRNA155. Science. 2007;316:604-8.

62 Johnnidis JB, Harris MH, Wheeler RT, et al. Regulation of progenitor cell proliferation and granulocyte function by microRNA-223. Nature. 2008;451:1125-9.

63 De Lencastre A, Pincus Z, Zhou K, Kato M, Lee SS, Slack FJ. MicroRNAs both promote and antagonize longevity in C. elegans. Curr Biol. 2010;20:2159-68.

64 Ito T, Yagi S, Yamakuchi M. MicroRNA-34a regulation of endothelial senescence. Biochem Biophys Res Commun. 2010;398:735-40.

65 Dimmeler S, Nicotera P. MicroRNAs in age-related diseases. EMBO Mol Med. 2013;5:180-90.

66 Kato M, Chen X, Inukai S, Zhao H, Slack FJ. Age-associated change in expression of small noncoding RNAs, including microRNAs, in C. elegans. RNA. 2011;17:1804-1820.

67 Ibanze-Ventoso C, Yang M, Guo S, Robins H, Padgett RW, Driscoll M. Modulated microRNA expression during adult lifespan in Caenorhabditis Elegans. Aging Cell. 2006;5:235-46. 


\subsection{Zielsetzung der Arbeit}

Im Rahmen der vorliegenden Arbeit soll die Expression von immunmodulatorischen microRNAs im PB von jungen und gealterten gesunden Probanden sowie Patienten mit CHF untersucht werden. Dabei soll ein Bezug auf Immunoseneszenz bzw. die Auswirkung von CHF auf das Immunsystem hergestellt werden. Im Rahmen dessen werden Leukozyten-, insbesondere Lymphozyten-Subpopulationen analysiert. Diese Ergebnisse sowie die klinischen Daten werden mit der Expression von microRNAs in Zusammenhang gebracht. 


\section{Material und Methoden}

\subsection{Studiendesign und Patientengut}

Bei dieser Arbeit handelt es sich um eine prospektive klinische Studie mit deskriptiver Auswertung und Analyse der erhobenen Daten. Die Studie wurde im Zeitraum von April 2010 und Februar 2011 in der kardiologischen Abteilung der Universitätsklinik Frankfurt am Main durchgeführt. Die Studie wurde von der Ethikkommission der Universität Frankfurt genehmigt und stimmt mit den Prinzipien der Deklaration von Helsinki überein. Alle Studienteilnehmer unterzeichneten nach erfolgter Aufklärung eine Einverständniserklärung.

Es wurde das peripher venöse Blut von den drei folgenden Gruppen untersucht: Patienten mit chronischer Herzinsuffizienz (CHF), alterskorrelierte gesunde (o/h) Kontrollen sowie junge gesunde $(\mathrm{y} / \mathrm{h})$ Kontrollen. Insgesamt wurden 61 Probanden in die Studie eingeschlossen (Abbildung 6). 


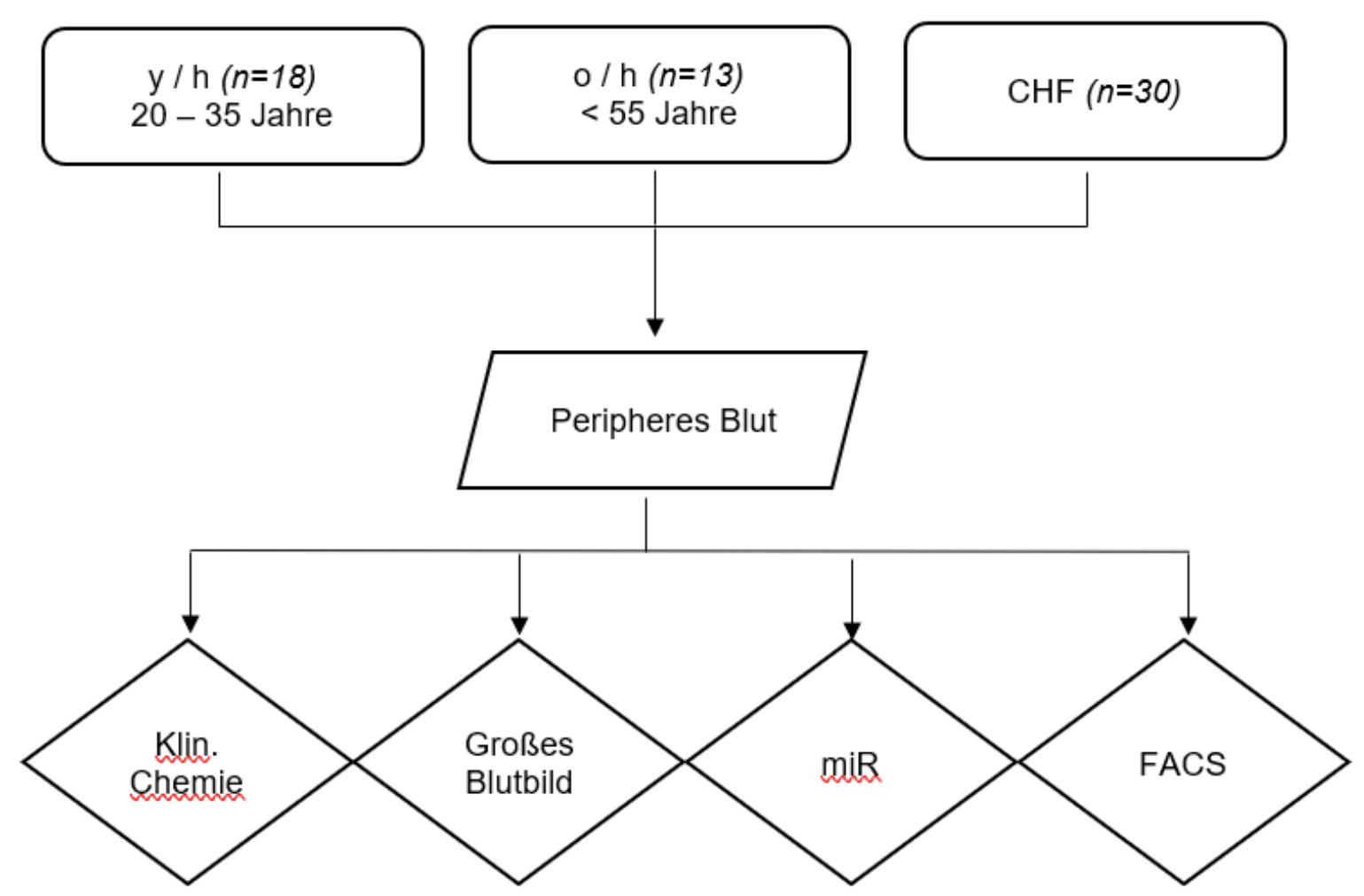

Abbildung 6: Studiendesign und Patientengut

Es wurden insgesamt 61 Probanden in die Studie eingeschlossen. Hierbei waren 18 Teilnehmer in der Gruppe der jungen gesunden Probanden, 30 Teilnehmer in der Gruppe der Patienten mit chronischer Herzinsuffizienz sowie 13 Teilnehmer bei den alterskorrelierten gesunden Probanden. Es wurde jeweils peripheres Vollblut entnommen, um die Analysen durchzuführen.

\subsubsection{Einschlusskriterien}

In der Gruppe der herzinsuffizienten Patienten wurden Patienten mit chronischer systolischer Linksherzinsuffizienz eingeschlossen. Einschlusskriterium waren eine ischämische oder dilatative Kardiomyopathie (ICM bzw. DCM) sowie eine dokumentierte schwere systolische ventrikuläre Dysfunktion, die mittels Echokardiographie gemessen wurde (linksventrikuläre Ejektionsfraktion [LVEF] $\leq 35$ $\%)$.

In die Kontrollgruppe der o/h Gruppe wurden Probanden im Alter von > 55 Jahren eingeschlossen, für die y/h-Kontrollgruppe wurden Probanden im Alter zwischen 2035 Jahren rekrutiert. 
Um die o/h sowie die CHF Gruppe vergleichen zu können, wurde in beiden Gruppen ein vergleichbares Alter der Probanden gewählt.

\subsubsection{Ausschlusskriterien}

Ausschlusskriterium für die CHF-Gruppe waren Patienten mit klinischen Zeichen oder Symptomen einer akuten kardialen Dekompensation, eines akuten Myokardinfarkts oder einer instabilen Angina Pectoris sowie einer stattgehabten Myokarditis <6 Monaten vor Einschluss in die Studie. Des Weiteren wurden Teilnehmer mit einer akuten Infektion oder einem entzündlichen Prozess (Creaktives Protein (CRP) $>1 \mathrm{mg} / \mathrm{dL}$; Leukozyten $>10 / \mathrm{nL}$ ) sowie Teilnehmer mit einer inflammatorischen, rheumatischen oder malignen Grunderkrankung in der Vorgeschichte von der Studie ausgeschlossen. Es wurden weiterhin keine Teilnehmer erfasst, die eine Impfung vor unter 3 Monate vor Einschluss in die Studie erfahren hatten, ebenso wenig wie Teilnehmer mit einer regelmäßigen Einnahme von Steroidhormonen.

Für die gesunden Probanden $(\mathrm{y} / \mathrm{h}, \mathrm{o} / \mathrm{h})$ waren neben den o.g. Kriterien weitere Ausschlusskriterien das Vorhandensein bekannter Erkrankungen, insbesondere Diabetes Mellitus, onkologische Erkrankungen sowie Hinweise auf hämatologische Erkrankungen im Blutbild.

Für die y/h-Gruppe war zudem jegliche Einnahme von Medikamenten ein Ausschlusskriterium für die Teilnahme an der Studie.

In der o/h-Gruppe wurden zudem bis zu zwei antihypertensive Medikamente toleriert, wenn es zeitglich keine in der Echokardiographie gemessene Zeichen für eine kardiale Hypertrophie oder diastolische Dysfunktion gab. 


\subsection{Primärmaterial, Probengewinnung}

Jedem Studienteilnehmer wurde zwischen 7 und 9 Uhr morgens im nüchternen Zustand PB abgenommen und innerhalb von drei Stunden verarbeitet.

Für die Messung der Routinediagnostik (großes Blutbild, klinische Chemie) wurden EDTA-PB, Citrat-Blut und Serumproben dem Zentrallabor der Universitätsklinik Frankfurt am Main zur Analyse überführt.

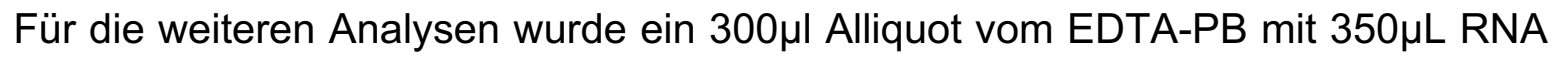
Trizol BD (Sigma, St Louis, MO, USA) gemischt und für die miRNA Expressionsanalyse verwendet. Das Gemisch wurde bis zur weiteren Präparation bei $-80^{\circ} \mathrm{C}$ eingefroren.

Weitere $1 \mathrm{~mL}$ PB wurden für die Analyse mittels Flow Zytometrie (FACS) benutzt.

\subsubsection{Isolation der zellulären microRNAs}

Zur Isolation der microRNAs aus den Zellen wurde RNA mithilfe eines MiRNeasy mini Isolationskit nach Anweisungen des Herstellerprotokolls (Qiagen, Valencia, CA, USA) isoliert. Hierzu wurden die eingefrorenen, in Trizol aufgenommen Zellen bei Raumtemperatur aufgetaut. Nach Zugabe von $140 \mu$ l Chloroform wurden die Zellen 2 min bei Raumtemperatur stehengelassen und im Anschluss daran 15 min bei $15000 \times$ g zentrifugiert. Der entstandene Interphasering mit der enthaltenen RNA wurde ab-pipettiert und mit 150 $\mu 100 \%$ Ethanol vermischt. Diese Lösung wurde auf eine RNeasy Säule pipettiert und $15 \mathrm{sec}$ bei $\geq 8000 \times \mathrm{g}$ bei $4^{\circ} \mathrm{C}$ zentrifugiert. Das Eluat wurde verworfen, die Säule mit der Probe auf ein neues washing tube gesetzt, $700 \mu \mathrm{l}$ RWT Puffer auf die Säule pipettiert und $15 \mathrm{sec}$ bei $\geq 8000 \times \mathrm{g}$ bei

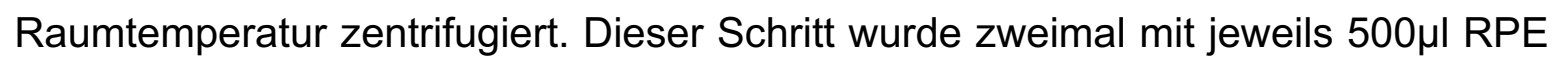
Puffer wiederholt, wobei bei dem letzten Waschvorgang für $1 \mathrm{~min}$ bei Raumtemperatur zentrifugiert wurde.

Das Eluat wurde verworfen und die restliche Probe wieder in ein neues washing tube gesetzt und $1 \mathrm{~min}$ bei $24.000 \mathrm{~g}$ bei Raumtemperatur zentrifugiert. Die getrocknete

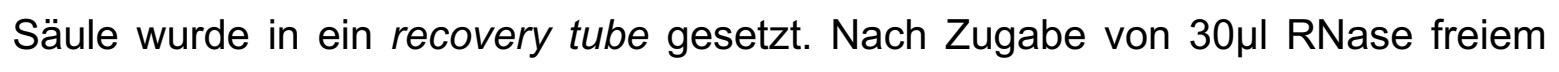
Wasser auf die Säule wurde die Probe 1 min inkubiert und anschließend 1 min bei 12.000 x g bei Raumtemperatur zentrifugiert. 
Zur Lagerung der isolierten RNA wurde diese erneut bei $-80^{\circ} \mathrm{C}$ eingefroren.

\subsubsection{Reverse Transkription}

Zur weiteren Analyse der microRNA Expression erfolgte zuerst eine RT-PCR (engl.: reverse transcription polymerase chain reaction) mit der isolierten RNA. Dabei wird die zu RNA mittels des Enzyms reverse Transkriptase in komplementäre DNA (cDNA, engl.: complementary DNA) umgeschrieben, im Anschluss kann daraus eine Bestimmung der Expression mittels quantitativer PCR erfolgen.

Für die RT-PCR wurden spezifische microRNA RT-Primer (TaqMan MicroRNA assays Applied Biosystems, Foster City, CA, USA) im Rahmen des TaqMan MicroRNA Reverse Transcription Kits verwendet.

Für eine $15 \mu$ l Reaktion wurde folgendes Schema verwendet:

$\begin{array}{ll}\text { Nucleasefreies Wasser } & 7,16 \mu \mathrm{l} \\ \text { 10x RT Puffer } & 1,5 \mu \mathrm{l} \\ \text { dNTP Mix } & 0,15 \mu \mathrm{l} \\ \text { 5x RT-Primer (Kit) } & 3 \mu \mathrm{l} \\ \text { RNAse Inhibitor } & 0,19 \mu \mathrm{l} \\ \text { Multiscribe RT Enzym } & 1 \mu \mathrm{l}\end{array}$

Dieser $13 \mu \mathrm{l}$ Mix wurde jeweils mit $2 \mu \mathrm{l}$ RNA (Konzentration von $4 \mathrm{ng} / \mu \mathrm{l}$ ) versetzt. Der Reaktionsansatz wurde 5 min auf Eis inkubiert. Anschließend erfolgte die reverse Transkription für $30 \mathrm{~min}$ bei $16^{\circ} \mathrm{C}$, dann $30 \mathrm{~min}$ bei $42^{\circ} \mathrm{C}$. Durch 5 min bei $85^{\circ} \mathrm{C}$ wurde die reverse Transkriptase inaktiviert. Anschließend wurde die resultierende cDNA für die Durchführung der quantitativen Polymerase-Kettenreaktion auf Eis aufbewahrt, oder für spätere Analysen bei $-80^{\circ} \mathrm{C}$ gelagert.

Die resultierende cDNA wurde bis zur quantitativen Polymerase-Kettenreaktion auf Eis aufbewahrt bzw. bei $-80^{\circ} \mathrm{C}$ gelagert. 


\subsubsection{Quantitative Polymerase-Kettenreaktion (qPCR)}

Um die Expressionslevel der miR-181a, b, c, miR-34a, miR-146a, miR-155 und miR$223 \mathrm{zu}$ bestimmen wurde die quantitative Polymerase-Kettenreaktion (qPCR) in einem Reaktionsvolumen von $20 \mu \mathrm{l}$ durchgeführt. Hierbei wurden TaqMan MicroRNA Assays und der Taqman Universal Master Mix (Applied Biosystems) verwendet.

Für eine $20 \mu$ l Reaktion galt das folgende Pipettierschema:

$\begin{array}{ll}\text { Nucleasefreies Wasser } & 6 \mu \mathrm{l} \\ \text { Taqman Universal MM Fast } & 10 \mu \mathrm{l} \\ \text { 20x Realtime-Primer (Kit) } & 1 \mu \mathrm{l}\end{array}$

Dieser $17 \mu \mathrm{l}$ Mix wurde jeweils mit $3 \mu \mathrm{l}$ von dem vorher hergestellten RT-Produkt versetzt.

Der entstandene 20 $\mathrm{\mu l}$ Mix wurde auf entsprechenden Öffnungen der PCR Platten pipettiert, welche anschließend mit einer Folie verschlossen wurde. Anschließend wurde die PCR-Platte bei 900 Umdrehungen für 5 min zentrifugiert.

Alle qPCR-Messungen wurden in einem 7900HT Fast Real-Time PCR System (Applied Biosystems) durchgeführt. Dabei wurde das folgende PCR-Programm verwendet:

Polymeraseaktivierung

$10 \min$ bei $95^{\circ} \mathrm{C}$

40 Zyklen:

Denaturierung

$15 \mathrm{sec}$ Bei $95^{\circ} \mathrm{C}$

Hybridisierung / Elongation

$60 \mathrm{sec}$ Bei $60^{\circ} \mathrm{C}$

\subsubsection{Auswertung}

Die Kalkulationen wurden unter Verwendung von $2^{\text {-ct }}$ Werten aufgestellt. Sämtliche Daten wurden als Expressionsverhältnis zum durchschnittlichen $2^{\text {-ct }}$ Wert von gesunden Probanden auf jeder Platte berechnet. 


\subsubsection{Durchflusszytometrische Analyse}

Die durchflusszytometrischen Analysen wurden in Kooperation mit der Klinik für Kinder- und Jugendmedizin der Universitätsklinik Frankfurt am Main durchgeführt.

Für jeden Studienteilnehmer wurde $1 \mathrm{~mL}$ PB mit 5-fach Kombinationen aus monoklonalen Antikörpern gegen CD3, CD4, CD8, CD19, CD27, CD45, CD56, IgD, Fluoreszeinisothiozyanat-markiertes IgM (FITC), Phycoerythrin (PE), PE-Texas Red (ECD), und PE-Cyanin (PC5 und PC87) gefärbt. Alle Reagenzien waren von Coulter Immunotech, Marseiles, France.

Es wurde ein automatisches Verfahren ohne zwischenzeitliches Waschen angewendet, um folgende Zellen zu bestimmen:

CD45 ${ }^{+}$Leukozyten

CD19 ${ }^{+}$B-Zellen, darunter

$\mathrm{CD}^{+} 9^{+} / \mathrm{CD} 27^{-} / \mathrm{lgD}{ }^{+}$naïve B-Zellen

CD19 $/$ CD27 + B-Gedächtniszellen

$\mathrm{CD}^{+} \mathrm{T}$-Zellen, darunter

CD4 ${ }^{+}$T-Helferzellen

$\mathrm{CD}^{+}$Zytotoxische T-Zellen

$\mathrm{CD}^{+} 6^{+} \mathrm{CD}^{-}{ }^{-} \mathrm{NK}$-Zellen

Alle Proben wurden in einem FC500 Flow Zytometer (Beckman Coulter) gemessen. Letztendlich wurden die absoluten Zahlen von den Leukozyten-Subpopulationen bestimmt.

\subsubsection{Statistische Analyse}

Alle statistischen Analysen wurden mithilfe SPSS für Mac-Os in der Version 19.0 durchgeführt (SPSS Inc., Chiacago, IL, USA).

Die Werte sind Mittelwerte \pm Standardfehler. Innerhalb der Gruppen wurden die Unterschiede mithilfe der one-way Varianzanalyse (ANOVA = analysis of variance) 
untersucht. Je nach Ergebnis aus dem Levine Test wurden für post-hoc Vergleiche der Bonferroni's Test oder der Dunett's T3-Test angewendet. Bivariate Korrelation wurde mithilfe der Pearson-Korrelation berechnet.

Statische Signifikanz wurde angenommen, wenn die Nullhypothese bei $p<0,05$ abgelehnt werden konnte. 


\section{Ergebnisse}

\subsection{Klinische Studiengruppe}

Tabelle 1: Charakteristika der Studienkohorte

\begin{tabular}{|c|c|c|c|}
\hline & CHF & $\mathrm{o} / \mathrm{h}$ & $y / h$ \\
\hline$n$ & 18 & 13 & 30 \\
\hline ICM & 11 & & \\
\hline DCM & 7 & & \\
\hline männlich / weiblich & $16 / 2$ & $10 / 3$ & $22 / 8$ \\
\hline Alter (Jahre) & $64(51-87)$ & $64(57-72)$ & $25(21-34)$ \\
\hline DM II (ja / nein / nb) & $5 T / 11 / 2$ & $0 / 9 / 4$ & $0 / 30 / 0$ \\
\hline aHT (ja / nein / nb) & $9 / 7 / 2$ & $2 / 11 / 0$ & $0 / 30 / 0$ \\
\hline LVEF (\%) & $26(15-35)$ & Normal & Normal \\
\hline NYHA (I / II / III / IV) & $1 / 13 / 4 / 0$ & & \\
\hline NT-proBNP (pg/mL) & $1873.5 \pm 2778$ \# & $76,8 \pm 91,5$ & $27,7 \pm 30,3$ \\
\hline Kreatinin $(\mathrm{pg} / \mathrm{mL})$ & $1,13 \pm 0,31$ \# & $0,86 \pm 0,16$ & $0,9 \pm 0,15$ \\
\hline $\mathrm{CRP}(\mathrm{mg} / \mathrm{dL})$ & $0,250,25 \pm 0,26$ \# & $0,17 \pm 0,18$ & $0,08 \pm 0,09$ \\
\hline Hämoglobin (mg/dL) & $14,0 \pm 1,0$ & $14,5 \pm 1,1$ & $14,5 \pm 1,5$ \\
\hline Leukozyten / nL & $7,6(4,8-9,9)^{\#}$ & $6,2(4,1-9,2)$ & $6,2(3,6-9,9)$ \\
\hline
\end{tabular}

Medikation

\begin{tabular}{|c|c|c|c|}
\hline Beta-Blocker (ja / nein) & $18 / 0$ & $0 / 13$ & $0 / 30$ \\
\hline ACEI/ARB (ja / nein) & $18 / 0$ & $2 / 11$ & $0 / 30$ \\
\hline Diuretika (ja / nein) & $15 / 3$ & $1 / 12$ & $0 / 30$ \\
\hline Aldosteron-A (ja / nein) & $15 / 3$ & $0 / 13$ & $0 / 30$ \\
\hline Digitalis (ja / nein) & $12 / 6$ & $0 / 13$ & $0 / 30$ \\
\hline Statine (ja / nein) & $12 / 6$ & $0 / 13$ & $0 / 30$ \\
\hline Flowzytometrie & 18 & 13 & 30 \\
\hline PCR & 15 & 13 & 20 \\
\hline
\end{tabular}


Insgesamt wurden 61 Probanden anhand der o.g. Ein- und Ausschlusskritierien in die Studie eingeschlossen (Tabelle 1). Es bestand kein signifikanter Unterschied im Alter der Gruppen o/h und CHF. Zudem bestand kein signifikanter Unterschied in der Höhe von CRP zwischen o/h und CHF bzw. zwischen o/h und $\mathrm{y} / \mathrm{h}$.

\subsection{Assoziation zwischen Alterung und miR-181-Expression im PB}

In der vorliegenden Arbeit wurde der Effekt der Alterung auf die Expression der verschiedenen miR-181 Transkripte der miR-181 Familie evaluiert. Es zeigte sich bei allen miR-181 Transkripten eine altersabhängige Reduktion der Expressionslevel (Abbildung 7). Besonders ausgeprägt war der Effekt bei der miR181c (-1,5-fach, $p=0,02)$, ein Trend zeigte sich für miR-181a $(-1,3$-fach, $p=0,07$; Abbildung 7). Alle miR-181 Familienmitglieder zeigten eine inverse Korrelation der

Expressions-Level im PB mit steigendem Alter $(r=-0,4 ; p<0,01$ für miR-181a, $b$, und $\mathrm{c}$, jeweils).

\subsection{Assoziation zwischen CHF und miR-181-Expression im PB}

Neben dem Effekt der Alterung auf die Expression der miR-181 Mitglieder im PB, war eine Fragestellung der Arbeit, ob bzw. wie ihre Expression durch das Vorliegen einer CHF beeinflusst wird. Der im vorherigen Abschnitt beschriebene altersassoziierte Abfall der miR-181c wurde durch das Vorliegen einer CHF besonders deutlich verstärkt (Abbildung 7). Dagegen unterschieden sich die miR181a- bzw. miR-181b Level nicht signifikant zwischen den Gruppen o/h und CHF (Abbildung 7).

Beim Vergleich von CHF mit y/h zeigten die CHF-Patienten signifikant reduzierte Expressionslevel aller untersuchten miR-181 Mitglieder (miR-181a -1,5-fach, $p=$ 0,01; miR-181b, -1,4-fach, $p=0,02$; miR-181c, $-2,4$-fach, $p<0,01$; Abbildung 7). 

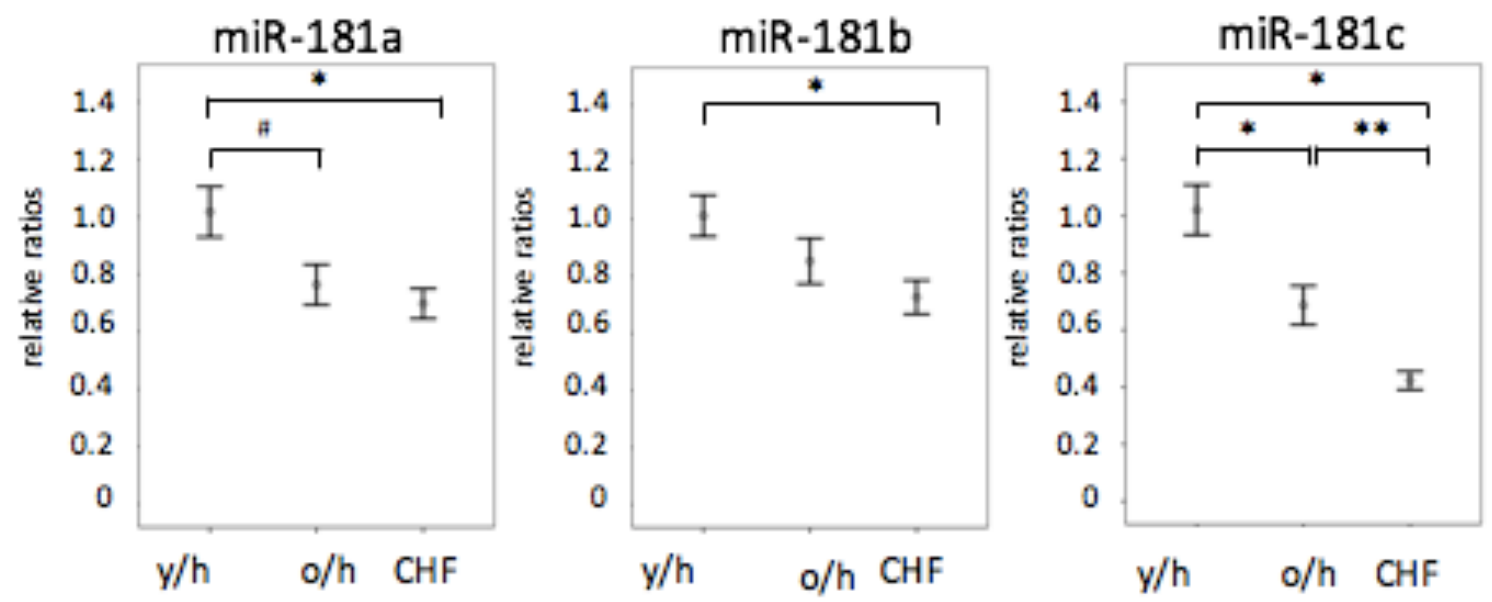

Abbildung 7: Expression der miR-181 Transkripte im PB

Die Expression der miR-181 Transkripte wurde mittels quantitativer PCR von RNA aus Vollblut von jungen/gesunden $(y / h ; n=20)$ und älteren/gesunden $(o / h$; $n=13$ ) Probanden sowie von Patienten mit Herzinsuffizienz (CHF; $n=15$ ) bestimmt. Dargestellt ist das relative Verhältnis technisch normalisierter PCRDaten in Relation zu den y/h Teilnehmern. $\left(\# p<0,1 ;{ }^{*} p<0,05 ;{ }^{* *} p<0,01\right)$.

\subsection{Korrelation zwischen Alterung sowie CHF und anderen immunmodulatorischen microRNAs im PB}

Neben den Expressionsanalysen der miR-181 Transkripte wurden im Rahmen dieser Arbeit noch weitere miRNAs mit bereits beschriebenen immunmodulatorischen Funktionen auf ihren Zusammenhang mit dem Alterungsprozess und dem Vorliegen einer CHF untersucht. Hierbei wurde sich auf folgende miRNAs fokussiert: MiR-34a, miR-155 und miR-146a sowie miR-223.

Es zeigte sich ein Trend hin zu einer altersabhängig erhöhten Expression von miR34a im Blut von gesunden Probanden (1,5-fach; $p=0,09$; Abbildung 8). Darüber hinaus war kein Effekt des Alters auf die Expression von miR-155 noch bei miR146a oder miR-223 nachweisbar.

Das Vorliegen einer CHF hatte im Vergleich zur o/h Kontrollgruppe keine signifikante Auswirkung auf die Expressionslevels von miR-34a, miR-146a oder miR-223. Dagegen zeigten sich in Hinblick auf miR-155 in der CHF-Gruppe signifikant reduzierte Expressionslevel im Vergleich zu o/h Probanden (-1,5-fach; $p=0,02$, Abbildung 8). 
Beim Vergleich der CHF-Patienten mit den y/h Kontrollen zeigten miR-155 (-1,5fach; $p=0,03)$ und miR-146a $(-1,5$ fach; $p<0,01)$ signifikante Unterschiede in der jeweiligen Expression (Abbildung 8).
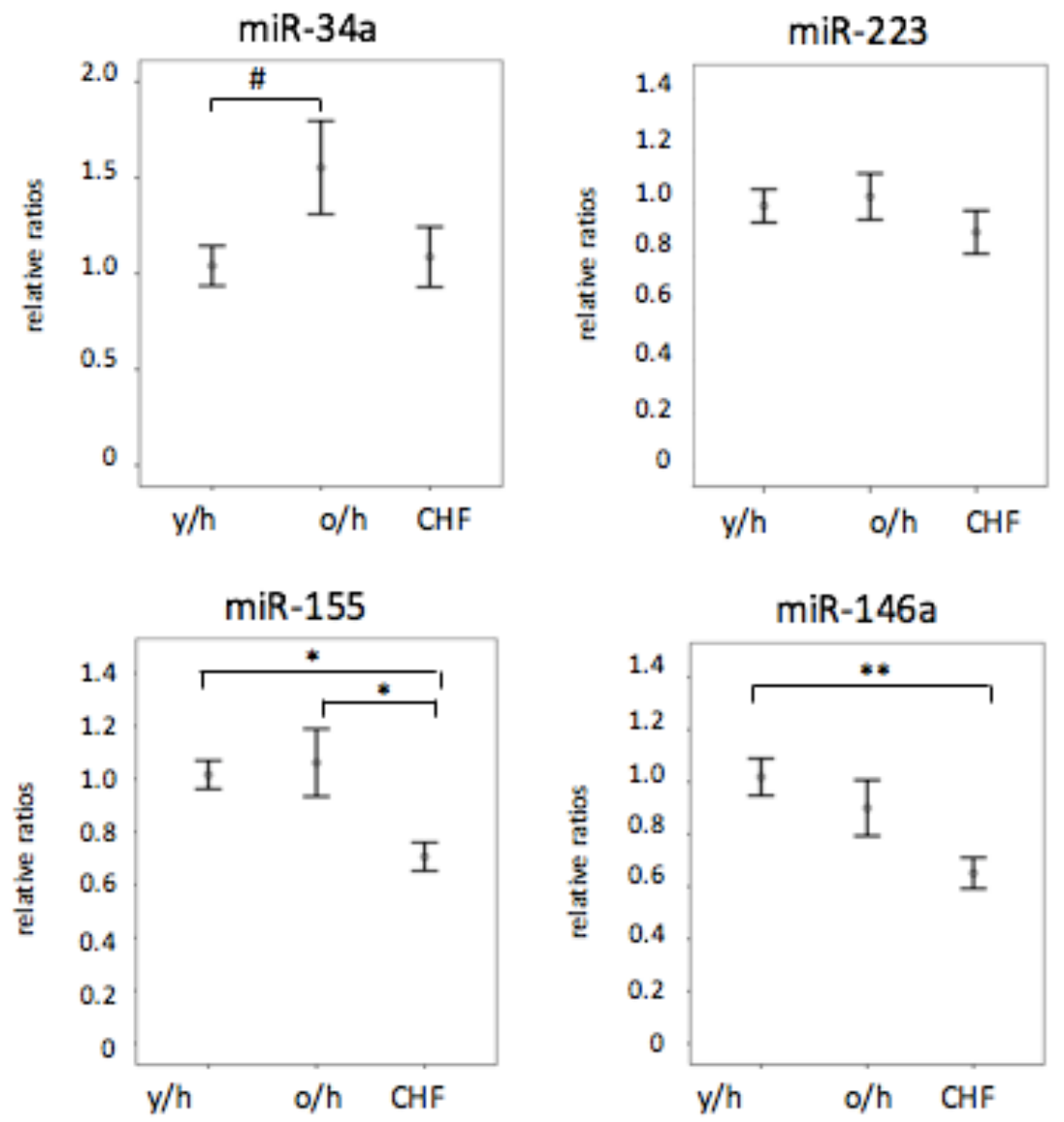

Abbildung 8: Expression weiterer immunmodulatorischer miRNAs im PB

Die Expression wurde jeweils mittels quantitativer PCR von RNA aus Vollblut von jungen/gesunden $(y / h ; n=20)$ und älteren/gesunden $(o / h ; n=13)$ Probanden sowie von Pateinten mit Herzinsuffizienz (CHF; $n=15)$ bestimmt. Dargestellt ist das relative Verhältnis technisch normalisierter PCR-Daten in Relation zu den y/h Teilnehmern. $\# p<0,1 ;{ }^{*} p<0,05 ;{ }^{* *} p<0,01$

\subsection{Untersuchung von Leukozyten und ihrer Subpopulationen im PB}

Ein weiteres Ziel der Arbeit war es, die Leukozyten- und ihre Subpopulationen im PB im Rahmen des Alterungsprozesses sowie bei Vorliegen einer CHF zu analysieren. 
In der hier untersuchten Studienkohorte zeigte sich kein Effekt des Alters alleine auf die absolute Zahl der Leukozyten, so gab es keinen signifikanten Unterschied in der o/h Gruppe im Vergleich zur y/h Gruppe (Abbildung 9). Bei Vorliegen einer CHF zeigte sich jedoch ein Trend zu einer höheren absoluten Zahl an Leukozyten im Vergleich zur o/h Gruppe (Abbildung 9).

Im Hinblick auf die Zusammensetzung der Leukozyten zeigte sich in der o/h Gruppe eine Tendenz zu reduzierten Lymphozytenzahlen im Vergleich zur y/h Gruppe. Bei Vorliegen einer CHF war dieser Effekt verstärkt, es stellte sich eine signifikante Abnahme im Vergleich zu o/h Probanden dar (o/h $30.0 \pm 2,92 \%$; CHF 23,3 $\pm 4,19 \%$; $-1,3$ fach; $p=0,04$; Abbildung 9), während sich die absoluten Zahlen nicht signifikant unterschieden (o/h 1,8 $\pm 0,22 / \mathrm{nl}$; CHF 1,7 $\pm 0,24 / \mathrm{nl}$ ).

Bei Betrachtung der myeloischen Zellen hatte der Alterungsprozess allein keine Auswirkungen auf die Fraktion der neutrophilen Granulozyten oder Monozyten. Lag jedoch eine CHF vor, so zeigten die Patienten hier im Vergleich zu y/h Gruppe eine signifikant höhere absolute Zahl an neutrophilen Granulozyten (o/h 3,79 \pm 0,74/nl; CHF 5,28 $\pm 0,72 / \mathrm{nl} ; 1,4$-fach; $p=0,01$ ).
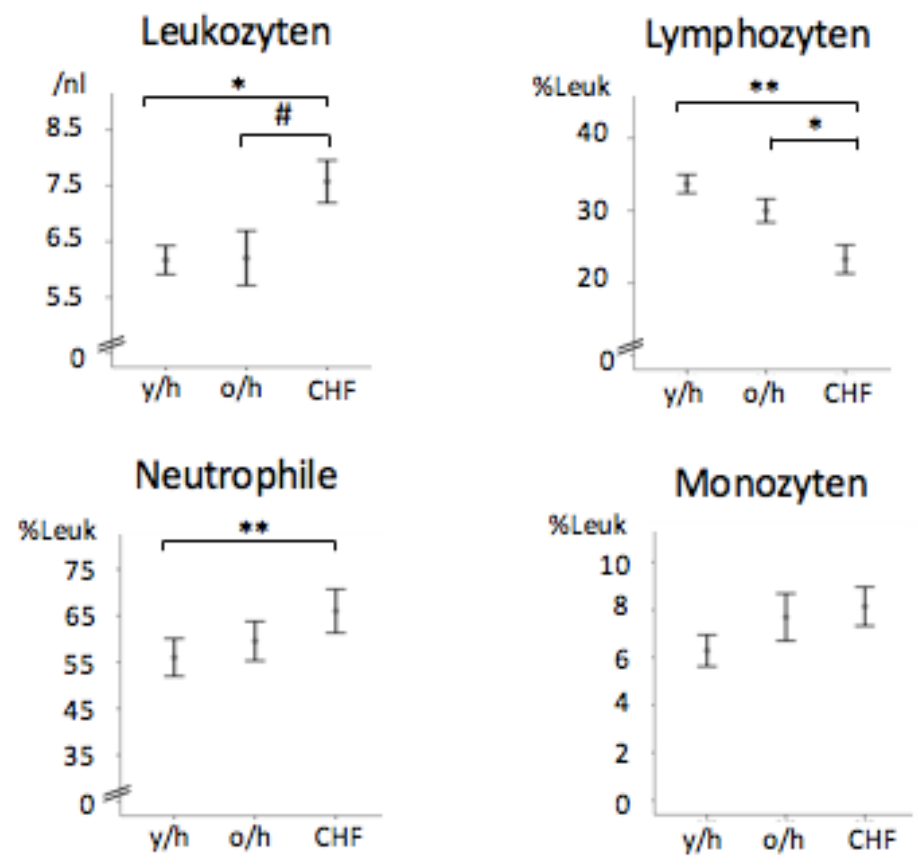

Abbildung 9: Verteilung der Leukozytensubtypen im PB

Dargestellt sind die absoluten Anzahlen der Leukozyten sowie die prozentualen Anteile der Subtypen in jungen $(\mathrm{y} / \mathrm{h} ; \mathrm{n}=20) \mathrm{bzw}$. gealterten gesunden Probanden $(\mathrm{o} / \mathrm{h}$; 
$n=13$ ) sowie Patienten mit chronischer Herzinsuffizienz (CHF; $n=15) . \# p<0,1 ;{ }^{*}<<0,05$;

$\left.{ }^{* *} p<0,01\right)$

\subsubsection{Alters- und CHF-bedingt Änderungen in B-Zellen und deren Subpopulationen}
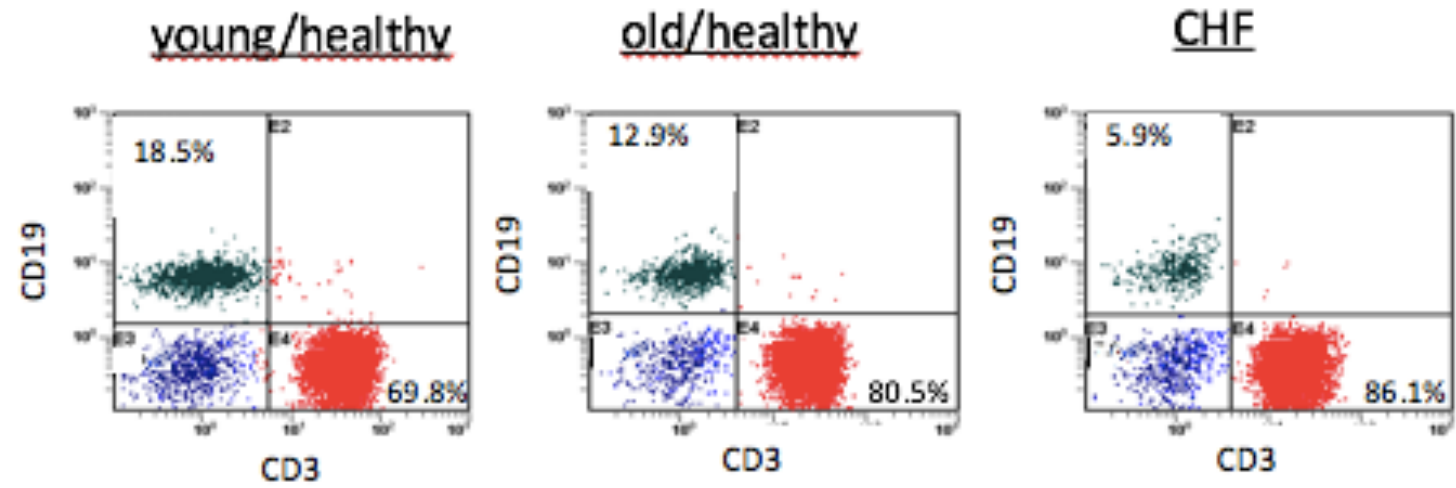

Abbildung 10: Repräsentativer Blot der Durchflusszytometrie mit Verteilung der Lymphozyten innerhalb der Leukozyten

Dargestellt sind die Fraktionen der CD19 ${ }^{+} \mathrm{B}$-Zellen sowie $\mathrm{CD}^{+}{ }^{+}$-Zelleninnerhalb der CD45 ${ }^{+}$Leukozyten im PB von jungen $(\mathrm{y} / \mathrm{h} ; \mathrm{n}=30)$ bzw. gealterten gesunden (o/h, $n=13$ ) Probanden sowie Patienten mit chronischer Herzinsuffizienz (CHF; n=18).

Innerhalb der Leukozyten (CD45 ${ }^{+}$Zellen im peripheren Blut) zeigt sich eine altersbedingte Abnahme des Gesamtanteils der B-Lymphozyten $\left(\mathrm{CD} 45^{+} / \mathrm{CD} 19^{+}\right)$, dies war zudem verstärkt bei Vorliegen von CHF (B-Zellen: y/h 4,37 $\pm 0,79 \%$ Leuk; o/h 3,22 \pm 0,78\%Leuk; CHF 2,24 $\pm 0.61 \%$ Leuk; Abbildung 11). Die absoluten

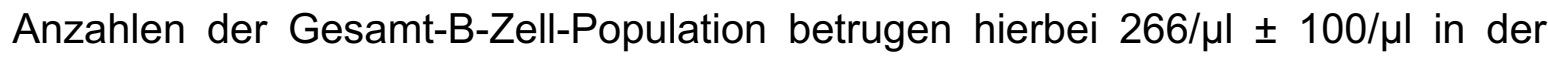

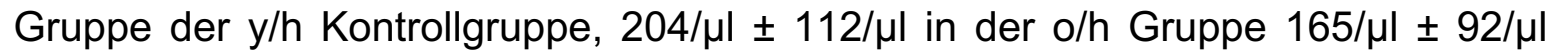
sowie in der Kohorte der CHF Patienten.

Auch die Subfraktion der naïven B-Zellen $\left(\mathrm{CD} 19^{+} / \mathrm{CD}^{2} 7^{-} / \mathrm{lgD} \mathrm{D}^{+}\right)$zeigte einen altersabhängigen Effekt mit reduzierten Anteilen, welcher durch $\mathrm{CHF}$ verstärkt wurde (y/h 3,4 \pm 0,7\%Leuk; o/h 2,49 \pm 0,69\%Leuk; CHF 1,74 \pm 0,53\%Leuk; Abbildung 11).

Im Gegensatz hierzu war der Anteil der B-Gedächtniszellen $\left(\mathrm{CD} 19^{+} / \mathrm{CD} 27^{+}\right)$bei gesunden Probanden in unserer Studienkohorte im Alter nicht verändert. Im Vergleich zwischen o/h und CHF-Patienten zeigte diese Population in der CHFGruppe jedoch eine signifikante Reduzierung (Abbildung 11). 

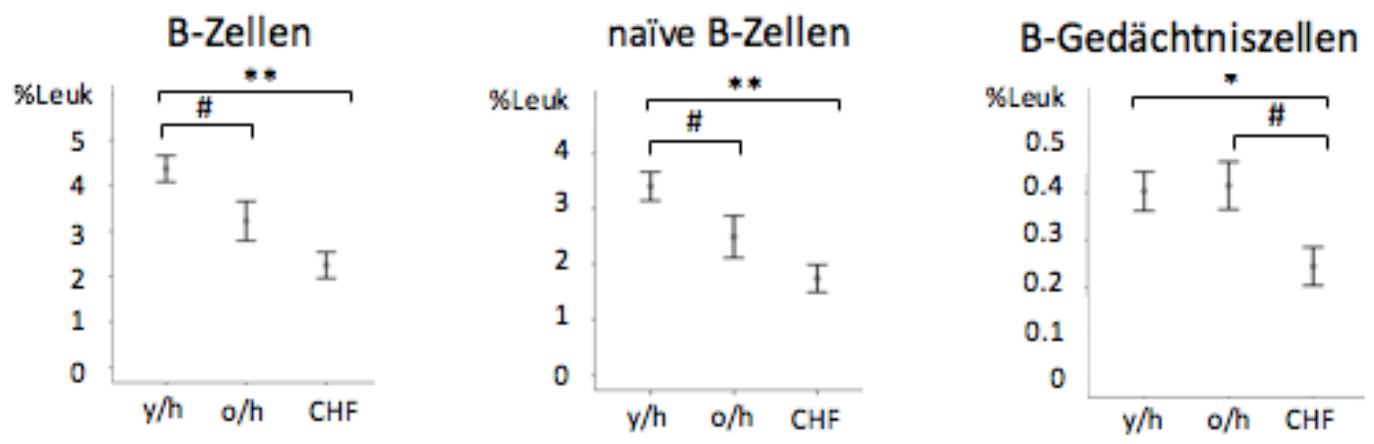

Abbildung 11: B-Zell-Subpopulationen im PB

Dargestellt sind die Anteile der B-Zellen $\left(\mathrm{CD} 19^{+}\right)$, der naiven B-Zellen (CD19 $/$CD27 $\left./ / g D^{+}\right)$sowie der B-Gedächtniszellen $\left(\mathrm{CD} 19^{+} / \mathrm{CD} 27^{+}\right)$innerhalb der $\mathrm{CD} 45^{+}$ Leukozyten im PB von jungen $(y / h ; n=20)$ bzw. gealterten gesunden $(o / h ; n=13)$ Probanden sowie Patienten mit chronischer Herzinsuffizienz (CHF; $n=15)$. $\# p<0,1$; ${ }^{*} p<0,05 ;{ }^{* *} p<0,01$

\subsubsection{Alters- und Herzinsuffizienz-bedingte Änderungen in T- Lymphozyten und deren Subpopulationen}

Bei der Analyse der T-Lymphozyten im PB zeigte sich in unserer Studienkohorte keine altersbedingte Abnahme der T-Lymphozyten-Fraktion im Gesamtanteil der Leukozyten, jedoch war ihr Anteil in der CHF Gruppe im Vergleich zu y/h signifikant reduziert (Abbildung 12).

Die Subfraktion der zytotoxischen T-Zellen zeigte einen altersabhängigen Abfall bei gesunden Probanden, der bei Vorliegen einer CHF besonders ausgeprägt war (Abbildung 12). Die absoluten Zahlen betrugen hierbei bei jungen gesunden Patienten 0,55 $\pm 0,15 / \mathrm{hl}$, bei gealterten gesunden Probanden 0,31 $\pm 0,092 / \mathrm{nl}$ und bei Patienten mit chronischer Herzinsuffizienz 0,34 $\pm 0076 / \mathrm{nl}$ (jeweils $p=0,01$ ).

Die Subfraktion der T-Helferzellen war in unserer Studienkohorte sowohl vom Alterungsprozess als auch vom Vorliegen einer CHF unbeeinflusst (Abbildung 12). 

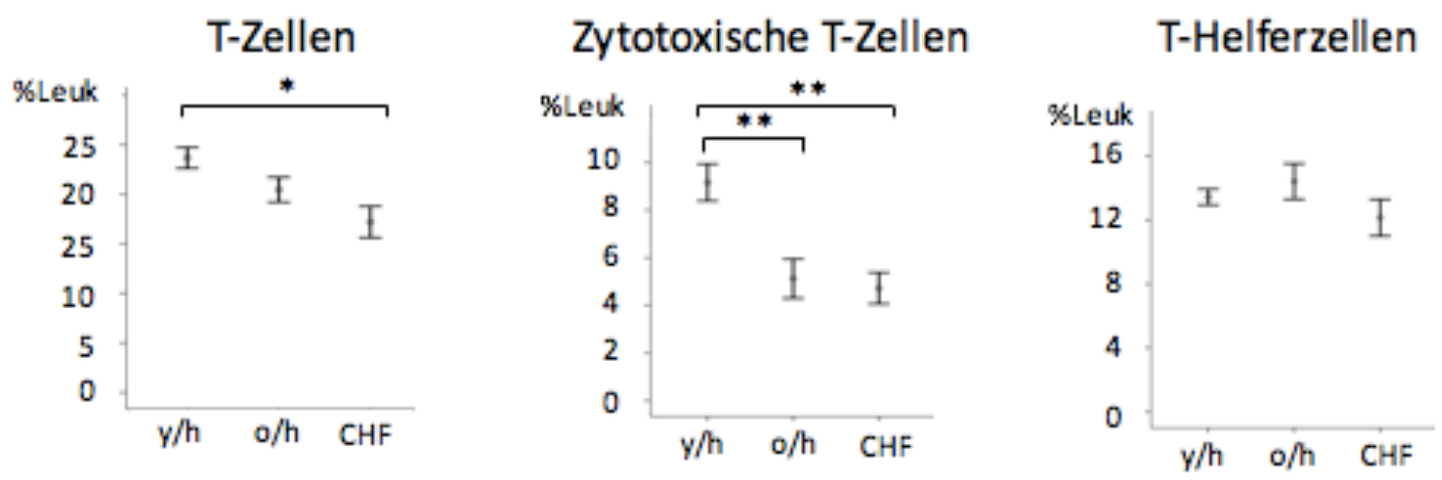

Abbildung 12: T-Lymphozyten-Populationen im PB

Dargestellt sind die Fraktion der T-Zellen $\left(\mathrm{CD}^{+}\right)$und deren Subpopulationen $\left(\mathrm{CD}^{+} / \mathrm{CD}^{+}\right.$zytotoxische T-Zellen sowie $\mathrm{CD} 3^{+} / \mathrm{CD} 4^{+}$T-Helferzellen) im PB von jungen $(y / h ; n=20)$ bzw. gealterten gesunden $(o / h ; n=13)$ Probanden sowie Patienten mit chronischer Herzinsuffizienz (CHF; $n=15)$. Es wird der prozentuale Anteil an Leukozyten gemessen angegeben. $\# p<0,1 ;{ }^{*} p<0,05 ;{ }^{* *} p<0,01$

\subsubsection{Alters- und CHF-bedingte Änderungen in NK-Zellen}

Innerhalb der gesunden Probanden in unserer Studienkohorte zeigte sich kein altersbedingter Effekt auf den Anteil der NK-Zellen in den PB-Leukozyten. Bei Vorliegen einer chronischen Herzinsuffizienz stellte sich eine signifikante 2-fache Reduktion der NK-Fraktion im Vergleich zu alterskorrelierten gesunden Probanden dar ( $p=0,03$; Abbildung 13). Die absoluten Zahlen betrugen hierbei $300 \pm 97 / \mu \mathrm{L}$ bei $y / h, 324 \pm 94 / \mu \mathrm{L}$ bei o/h und $214 \pm 53 / \mu \mathrm{L}$ bei CHF Gruppe (y/h vs. CHF $p=0,3$ ).

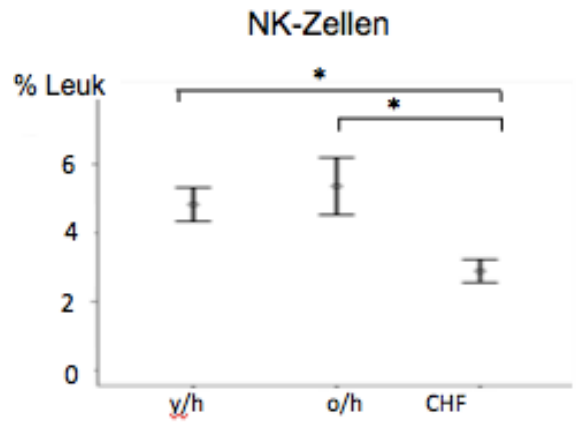

Abbildung 13: Fraktion der NK-Zellen im PB

Dargestellt sind die Anteile der NK-Zellen $\left(\mathrm{CD}^{-} / \mathrm{CD} 6^{+}\right)$innerhalb der Leuzkozyten $\left(C D 45^{+}\right)$im PB von jungen $(y / h ; n=20)$ bzw. gealterten gesunden $(o / h ; n=13)$ Probanden sowie Patienten mit chronischer Herzinsuffizienz (CHF; $n=15)$. $\# p<0,1$; ${ }^{*} p<0,05 ;{ }^{* *} p<0,01$ 


\subsection{Verteilung der Leukozyten-Subpopulationen in Abhängigkeit der CHF Ätiologie}

Zudem analysierten wir die Verteilung der Leuzkozytensubpopulationen im PB in Hinblick auf die zugrundeliegende Ätiologie der CHF.

Insbesondere innerhalb der B-Zellpopulationen stellten sich Unterschiede dar, hier zeigte sich in Hinblick auf den Gesamtanteil der B-Lymphozyten sowie den Anteil der naïven und der B-Gedächtnis-Zellen ein Trend für eine Reduzierung insbesondere bei Patienten mit ischämischer Genese der CHF im Vergleich zu einer dilatativen Kardiomyopathie (Abbildung 14).

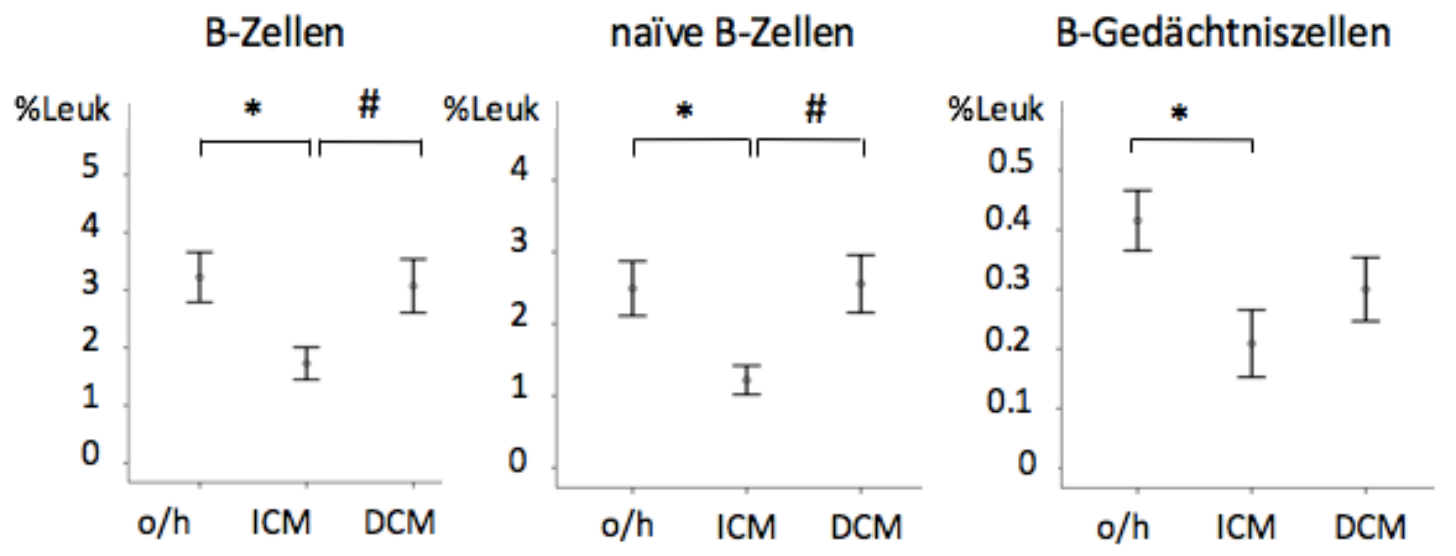

Abbildung 14: Fraktionen der B-Zellen in Abhängigkeit der Ätiologie bei CHF

Dargestellt sind die Anteile der B-Zellen $\left(\right.$ CD19 $\left.{ }^{+}\right)$, der naiven B-Zellen (CD19 ${ }^{+} / C D 27^{-}$ $\left./ / g D^{+}\right)$sowie der B-Gedächtniszellen $\left(\mathrm{CD} 19^{+} / \mathrm{CD} 27^{+}\right)$innerhalb der $\mathrm{CD} 45^{+}$ Leukozyten im PB von gealterten gesunden $(o / h ; n=13)$ Probanden sowie Patienten mit chronischer Herzinsuffizienz aufgrund ischämischer Genese (ICM, $n=11)$ oder dilatativer Kardiomyopathie (DCM, $n=7)$.\# $p<0,1 ;{ }^{*} p<0,05 ;{ }^{*} p<0,05 ;{ }^{* *} p<0,01$

Für andere Leukozyten- und Lymphozyten Subpopulationen konnten keine signifikanten Unterschiede zwischen den CHF-Gruppen festgestellt werden (Abbildung 15). 

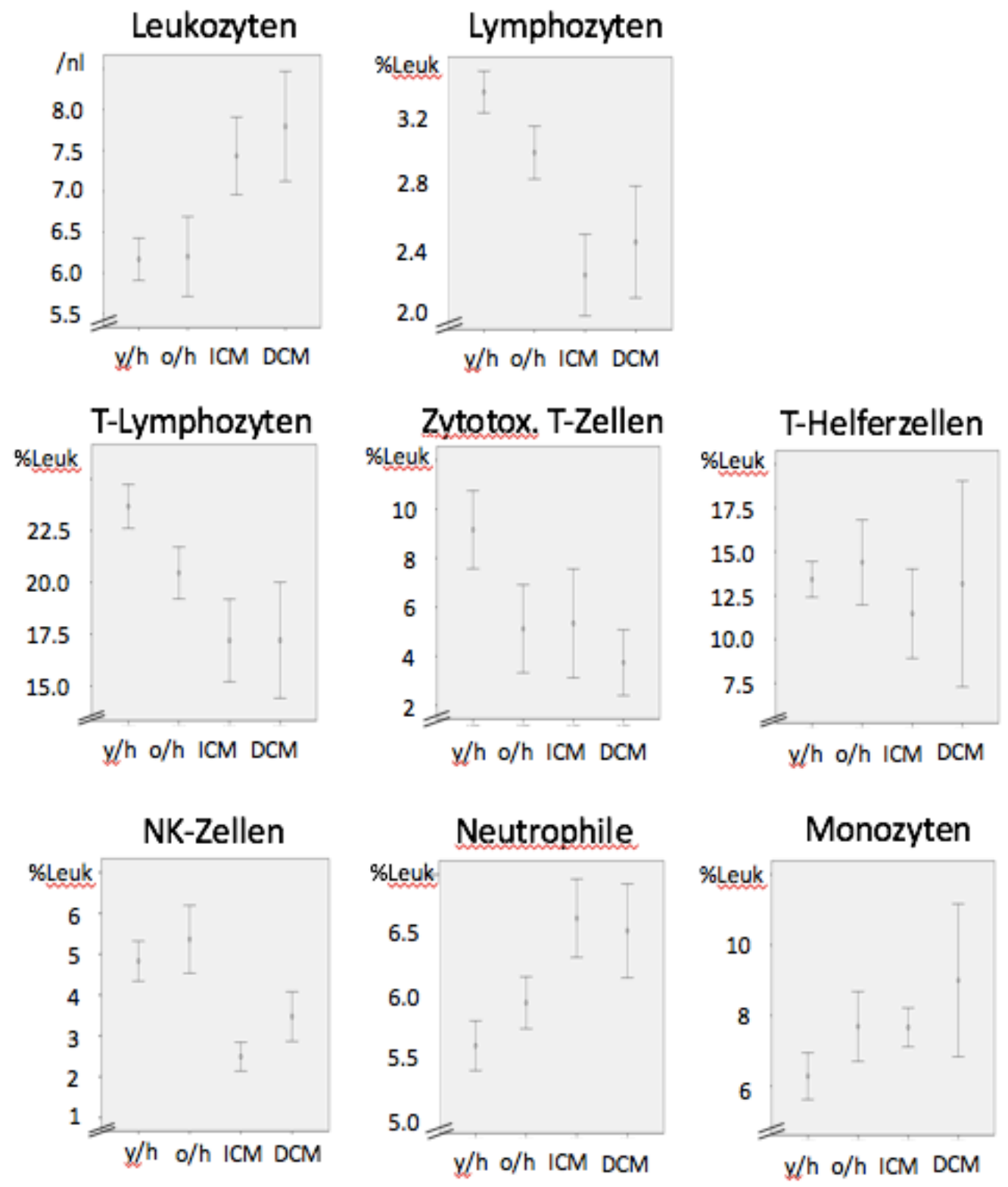

Abbildung 15: Anteile der Leukozyten-Subpopulationen im PB in Abhängigkeit der CHF Ätiologie

Dargestellt sind Leukozyten, die Fraktion der Lymphozyten, CD3+ T-Zellen, $\mathrm{p}<$ 0,$1 ;{ }^{*} p<0,05 ;{ }^{*} p<0,05 ;{ }^{* *} p<0,01 \quad$ sind die Anteile der B-Zellen, Zytotoxische T-Zellen (CD3+/CD8), T-Helfer-Zellen (CD3+/CD4+), NK-Zellen (CD3-/CE56+) im PB. von jungen gesunden Probanden $(y / h ; n=30)$ gealterten gesunden $(o / h ; n=13)$ Probanden sowie Patienten mit chronischer Herzinsuffizienz aufgrund ischämischer Genese (ICM, n=11) oder dilatativer Kardiomyopathie (DCM, $n=7$ ) 


\subsection{Zelltyp-spezifische Expression der miR-181 Mitglieder in humanem PB}

Bislang wurde für miR-181 eine bedeutende Rolle in der murinen B-Lymphopoese beschrieben. ${ }^{68,69}$ Um zu untersuchen, in welcher Fraktion humaner Leukozyten im PB miR-181 exprimiert wird haben wir CD19 ${ }^{+}$B-Zellen, CD14 ${ }^{+}$Monozyten sowie $\mathrm{CD}^{+} \mathrm{T}$-Zellen aus PB von $\mathrm{y} / \mathrm{h}$ separiert und in Hinblick auf die miRNA Expression analysiert. In den durchgeführten Untersuchungen zeigten die Mitglieder der miR181 Familie keine spezifische Anreicherung in B-Zellen im Vergleich zu T-Zellen, dagegen zeigte sich eine Tendenz zu erhöhter Expression in $\mathrm{CD}_{14}{ }^{+}$Zellen (Abbildung 16).
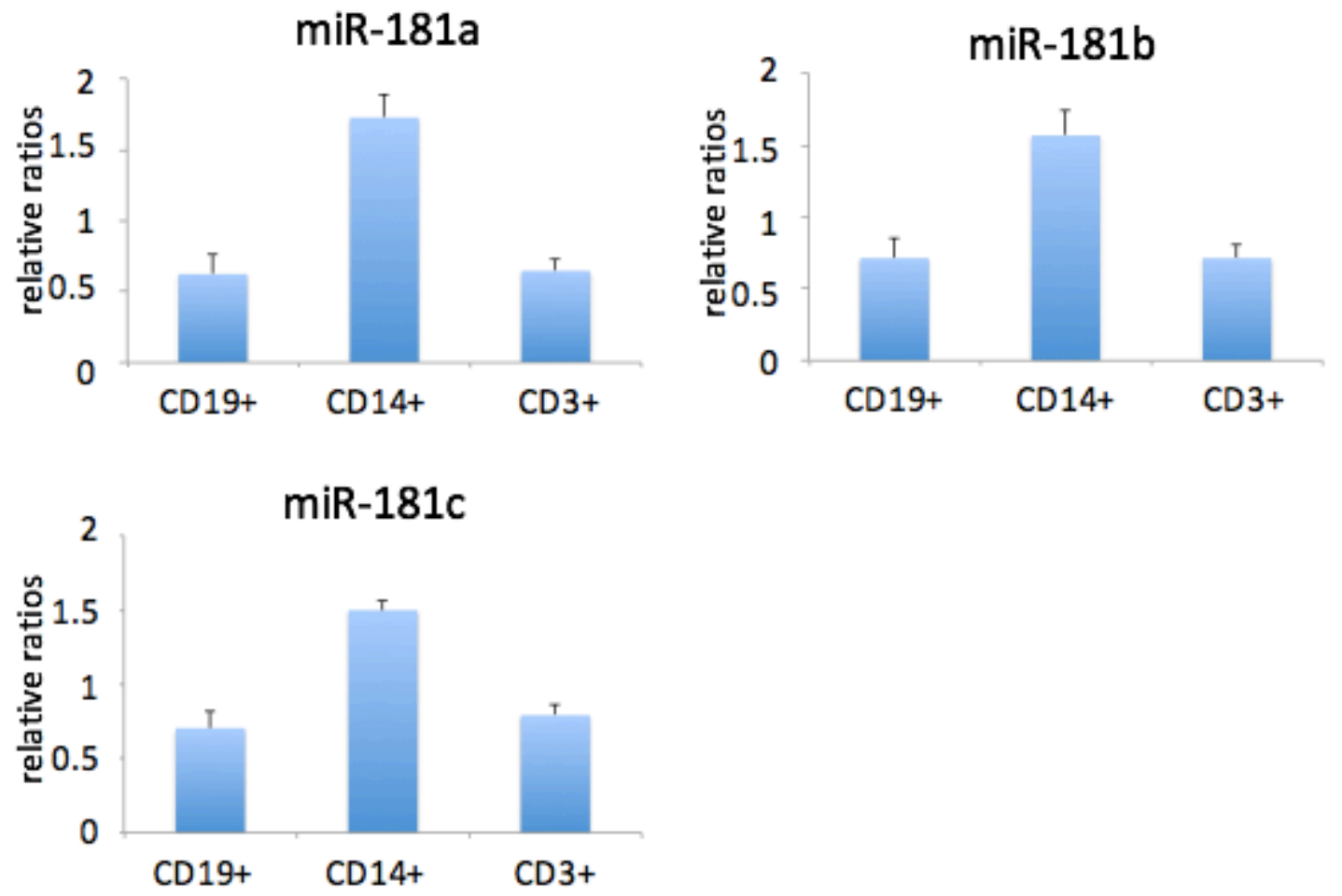

Abbildung 16: Expressionslevels der miR-181 Mitglieder in unterschiedlichen Zellfraktionen in humanem PB

68 Ramkissoon SH, Mainwaring LA, Ogasawara Y, et al. Hematopoietic-specific microRNA expression in human cells. Leuk Res. 2006;30:643-7.

69 Merkerova M, Belickova M, Bruchova H. Differential expression of microRNAs in hematopoietic cell lineages. Eur J Haematol. 2008;81:304-10. 


\subsection{Korrelationsanalysen der Expression von miR-181 Transkripten im PB}

Zur weiteren Beurteilung möglicher Assoziationen von Veränderungen in der Zusammensetzung der Leukozyten im peripheren Blut und der Expression von miR181 Transkripten haben wir Korrelationsanalysen durchgeführt (Tabelle 2).

Tabelle 2: Korrelationskoeffizienten von miR-181 Expressionslevels in Leukozyten bzw. deren Subpopulationen im PB

\begin{tabular}{llll} 
Gesamte Kohorte & miR-181a & miR-181b & miR-181c \\
\hline Leukozyten $/ \mu \mathrm{L}$ & $-0,29^{*}$ & $-0,32^{*}$ & $-0,36^{*}$ \\
Lymphozyten $/ \mu \mathrm{L}$ & $-0,04$ & 0,13 & 0,09 \\
T-Zellen $/ \mu \mathrm{L}$ & $-0,12$ & $-0,03$ & $-0,03$ \\
T-Helfer-Zellen $/ \mu \mathrm{L}$ & $-0,18$ & $-0,1$ & $-0,18$ \\
zytotox.T-Zellen $/ \mu \mathrm{L}$ & $-0,06$ & 0,01 & 0,06 \\
NK-Zellen $/ \mu \mathrm{L}$ & 0,02 & 0,13 & 0,11 \\
B-Zellen $/ \mu \mathrm{L}$ & $0,26^{\#}$ & 0,19 & $0,42^{* *}$ \\
Naïve B-Zellen $/ \mu \mathrm{L}$ & $0,29^{*}$ & 0,19 & $0,42^{* *}$ \\
B-Gedächtniszellen $/ \mu \mathrm{L}$ & $-0,07$ & $-0,04$ & 0,03 \\
Granulozyten $/ \mu \mathrm{L}$ & $-0,29$ & $-0,38^{*}$ & $-0,43^{* *}$ \\
Neutrophile $/ \mu \mathrm{L}$ & $-0,28^{\#}$ & $-0,37^{*}$ & $-0,41^{* *}$ \\
Monozyten $/ \mu \mathrm{L}$ & $-0,04$ & $-0,14$ & $-0,18$ \\
${ }^{\#} \mathrm{p}<0,1 ;{ }^{*}<0,05 ;{ }^{* *} \mathrm{p}<0,01$ & & &
\end{tabular}

Alle miR-181 Familienmitglieder zeigten eine inverse Korrelation mit der Zahl der zirkulierenden Leukozyten und neutrophilen Granulozyten im PB.

Die Expressionslevel der miR-181c korrelierten positiv mit zirkulierenden B-Zellen und der Subpopulation von naïven B-Zellen. Dieser Effekt war gering ausgeprägt auch in Hinblick auf miR-181a zu beobachten.

In unseren Untersuchungen zeigte kein Mitglied der miR-181 Familie eine signifikante Korrelation mit den zirkulierenden T-Lymphozyten oder ihren Subpopulationen. 


\subsection{Korrelation anderer immunmodulatorischer microRNAs in Leukozyten bzw. deren Subpopulationen}

Um die Assoziation der weiteren untersuchten immunmodulatorischen microRNAs mit den Veränderungen der Zusammensetzung der Immunzellen zu prüfen, führten wir auch hier Korrelationsanalysen durch (Tabelle 3).

Tabelle 3: Korrelationskoeffizienten von Expressionslevels immunmodulatorischer microRNAs in Leukozyten-Subpopulationen im PB

\begin{tabular}{lllll} 
Gesamte Kohorte & miR-34a & miR-155 & miR-146a & miR-223 \\
\hline Leukozyten $/ \mu \mathrm{L}$ & $-0,22$ & $-0,32^{*}$ & $-0,22$ & 0,20 \\
Lymphozyten $/ \mu \mathrm{L}$ & 0,05 & 0,20 & 0,11 & $-0,04$ \\
T-Zellen $/ \mu \mathrm{L}$ & 0,17 & 0,15 & $-0,02$ & $-0,09$ \\
T-Helfer-Zellen $/ \mu \mathrm{L}$ & 0,13 & $-0,05$ & $-0,07$ & 0,05 \\
zytotox.T-Zellen $/ \mu \mathrm{L}$ & 0,15 & 0,25 & 0,03 & $-0,15$ \\
NK-Zellen $/ \mu \mathrm{L}$ & 0,09 & $0,33^{*}$ & 0,14 & 0,04 \\
B-Zellen $/ \mu \mathrm{L}$ & $-0,08$ & 0,20 & $0,41^{* *}$ & $0,37^{* *}$ \\
Naïve B-Zellen $/ \mu \mathrm{L}$ & $-0,07$ & 0,21 & $0,41^{* *}$ & $0,38^{* *}$ \\
B-Gedächtniszellen $/ \mu \mathrm{L}$ & $-0,03$ & $-0,06$ & 0,13 & $0,29^{*}$ \\
Granulozyten $/ \mu \mathrm{L}$ & $-0,19$ & $-0,48^{* *}$ & $-0,35^{*}$ & $0,26^{\#}$ \\
Neutrophile $/ \mu \mathrm{L}$ & $-0,18$ & $-0,48^{* *}$ & $-0,34^{*}$ & $0,26^{\#}$ \\
Monozyten $/ \mu \mathrm{L}$ & $-0,25^{\#}$ & -012 & $-0,16$ & $-0,04$ \\
${ }^{*} \mathrm{p}<0,1 ;{ }^{*} \mathrm{p}<0,05 ;{ }^{* *} \mathrm{p}<0,01$ & & & &
\end{tabular}

Die Expression von miR-34a zeigte keine Korrelation mit den zirkulierenden BLymphozyten oder ihren Subpopulationen. Es stellte sich eine signifikante Korrelation zwischen der Anzahl der zirkulierenden B-Lymphozyten sowie naïven BZellen und der Expression von miR-146 sowie miR-223 dar. Die Expressionslevel von miR-223 korrelierten zudem auch positiv mit der Anzahl der zirkulierenden BGedächtniszellen.

Die Anzahl der zirkulierenden Granulozyten sowie Neutrophilen zeigte eine signifikante negative Korrelation mit den Expressionslevel von miR-155 sowie miR- 
146a, und eine schwache positive Korrelation mit den Expressionslevel von miR223.

Eine signifikante Assoziation mit den NK-Zellen zeigte sich in unseren Untersuchungen lediglich bei miR-155.

Ähnlich wie bei den Mitgliedern der miR-181 Familie konnten in unseren Untersuchungen keine Korrelation der gemessenen microRNAs mit den zirkulierenden T-Lymphozyten oder ihren Subsets nachgewiesen werden.

\subsection{Assoziation zwischen CHF und miRNA-Levels und Immunzellen}

Des Weiteren wurden die Daten in Hinblick auf eine mögliche Assoziation zwischen der Schwere der CHF und den miRNA-181-Levels analysiert. Als Parameter für eine fortgeschrittene $\mathrm{CHF}$ wurden hierbei die linksventrikuläre Ejektionsfraktion sowie der Plasmaspiegel von N-terminal NT-proBNP hinzugezogen. Wir untersuchten, ob eine reduzierte LV-EF bzw. ein erhöhter Plasmaspiegel NT-proBNP mit veränderten Expressionslevels der miR181-Familie einhergingen. Für keine der untersuchten microRNAs zeigte sich eine signifikante Korrelation.

Weiterhin wurde untersucht, ob die LV-EF und die NT-proBNP-Plasmaspiegel mit einer Änderung von Immunzellen im PB vergesellschaftet sind. Hier zeigte sich eine inverse Korrelation zwischen den zirkulierenden $\mathrm{CD} 3^{+}$Lymphozyten und PlasmaNT-pro-BNP-Levels $(r=-0,64, p<0,001)$. Ähnlich verhielten sich die LymphozytenSubpopulationen (B Zellen, $r=-0,55, p=0,02$; T-Helfer-Zellen, $r=-0,63, p<0,01$ ).

Daneben zeigte sich eine positive Korrelation zwischen der LV-EF und der Fraktion zirkulierender NK-Zellen $(r=0,55 ; p=0,02)$. 


\section{Diskussion}

Im Laufe des Alterungsprozesses kommt es zu einer altersbedingten Abnahme der Immunfunktionen. Veränderungen des Immunsystems spielen auch eine signifikante Rolle im Rahmen von chronischer Herzinsuffizienz, sie führen ebenfalls zu erhöhten Infektanfälligkeiten und gehen mit einer Verschlechterung der Prognose einher. $^{70}$

Die Beteiligung von microRNAs im Alterungsprozess ist bereits seit längerem entdeckt und beschrieben. ${ }^{63-64}$ Für die microRNA-34a wurde bereits gezeigt, dass sie im Laufe des Alterungsprozesses in Caenorhabditis elegans hochreguliert wird, ${ }^{71}$ ebenso wie in in-vitro gealterten kultivierten Endothelzellen, die aus unterschiedlichen Geweben, wie z.B. Hirn, Herz, Milz und Leber sowie aus dem PB, gewonnen wurden. ${ }^{72}$ Auch die im Rahmen unserer Studie durchgeführten Untersuchungen decken sich mit den bisherigen Ergebnissen: Die miR-34 Expression korrelierte positiv mit steigendem Alter. Darüber hinaus zeigte unsere Arbeitsgruppe eine Hochregulation der miR-34a in mononukleären Knochenmarkszellen (BMCs) aus Patienten mit chronischer Herzinsuffizienz; eine Inhibierung der miR-34a in BMCs führte zu einer reduzierten Apoptose in vitro und Verbesserung nach Myokardinfarkt bei Mäusen. ${ }^{73}$ In unseren Untersuchungen zeigte die miR-34a im PB keine Erhöhung in CHF Patienten, was nahelegt, dass die miR-34 möglicherweise in BMCs und im PB unterschiedlich reguliert ist.

In unserer Studie beobachteten wir eine alters- und CHF-assoziierte Dysregulation von microRNAs, die im Immunsystem beteiligt sind. Wir untersuchten in dieser Arbeit

70 Fildes JE, Shaw SM, Yonan N, Williams SG. The immune system and chronic heart failure. Is the heart in control? J Am Coll Cardiol. 2009;53(12):1013-20.

71 Yang J, Chen D, He Y, et al. MiR-34 modulates Caenorhabditis elegans lifespan via repressing the autophagy gene atg9. Age (Dordr). 2013;35(1):11-22.

72 Li N, Bates DJ, An J, Terry DA, Wang E. Up-regulation of key microRNAs, and inverse downregulation of their predicted oxidative phosphorylation target genes, during aging in mouse brain. Neurobiol Aging. 2011;32:944-55.

$73 \mathrm{Xu} \mathrm{Q}$, Seeger FH, Castillo J, et al. Micro-RNA-34a contributes to the impaired function of bone marrow-derived mononuclear cells from patients with cardiovascular disease. J Am Coll Cardiol. 2012;59:2107-17. 
die miR-181 Familie im Verlauf des Alterungsprozesses sowie der CHF. In unseren Untersuchungen zeigten alle Mitglieder der miR-181 Familie einen altersabhängigen Rückgang der Expression, dieser Effekt war besonders deutlich bei der microRNA181a und c. Darüber hinaus war die miR-181 bei Patienten mit CHF deutlicher stärker reduziert im Vergleich zu alterskorrelierten gesunden Probanden.

Die miR-181 ist bekannt für ihre Rolle in der Lymphozyten Differenzierung und Funktion. Sie reguliert die B-Lymphopoese positiv. ${ }^{58}$ Auch in unserer Studie haben wir eine Assoziation mit B-Zellen gesehen, die Expression von mir-181 korrelierte signifikant mit der Anzahl zirkulierender B-Zellen im humanem peripheren Blut. So kam es bei einer reduzierten Expression von miR-181 zu einem Abfall der BLymphozyten im PB.

Eine Involvierung der miR-181 in der T-Zell Reifung und Immunfunktion wurde bereits beschrieben. ${ }^{74-75}$ In unseren Untersuchungen zeigte sich keine alterskorrelierte Assoziation der miR-181 Familienmitglieder mit T-Zellen oder ihren Subsets. Es wäre jedoch möglich, dass die miR-181 in humanen Lymphozyten eher die T-Zell-Funktionen beeinflusst als ihre Differenzierung. ${ }^{75}$ Hierzu zeigte eine Publikation, dass ein Abfall der miR-181a Expression mit einer eingeschränkten TZell-Rezeptor-Sensitivität einhergeht. ${ }^{76}$ Ein klinischer Ansatzpunkt hierzu wäre, dass es bei Patienten mit chronischer Herzinsuffizienz neben der reduzierten Zahl an zytotoxischen T-Zellen sowie B-Zellen zu einer miR-181-vermittelten beeinträchtigten T-Zell-Rezeptor-Antwort kommt, die zu einer Dysregulation der Immunfunktionen beiträgt. Inwiefern diese Hypothese zutrifft, müsste in einer Studie mit entsprechendem Studiendesign evaluiert werden.

Was die NK-Zellen betrifft, waren diese in unseren Untersuchungen bei Patienten mit CHF signifikant reduziert im Vergleich zu alterskorrelierten gesunden

74 Liu G, Min H, Yue S, Chen CZ. Pre-MiRNA loop nucleotides control the distinct activities of mir181a-1 and mir-181c in early T cell development. PLoS One 2008; 2008;3:e3592.

$75 \mathrm{Li}$ QJ, Chau J, Ebert PJ, et al. miR-18 1a is an intrinsic modulator of T cell sensitivity and selection. Cell. 2007; 129:147-61.

76 Li G, Yu M, Lee WW, et al. Decline in miR-181a expression with age impairs $T$ cell receptor sensitivity by increasing DUSP6 activity. Nat Med. 2012;18(10):1518-24. 
Probanden. Dies deckt sich mit den bisher erhobenen Ergebnissen von Yao et al. ${ }^{77}$ NK-Zellen von CHF-Patienten zeigten in vergangen Studien eine eingeschränkte zytotoxische Funktion. ${ }^{78}$ Eine weitere Publikation zeigte, dass die miR-181 in der NK-Zell Biologie mit einer positive regulierende Funktion assoziiert ist. ${ }^{79}$ Hier führte eine Überexpression von miR-181a/b in CD34+ hämatopoetischen Vorläuferzellen aus Nabelschnurblut zu vermehrt CD56+ NK-Zellen sowie zu einer höheren zytotoxische Aktivität von NK-Zellen im PB. Unsere Arbeit konnte keine Assoziation der miR-181 mit den zirkulierenden NK-Zellen gezeigt werden.

Es wird angenommen, dass Veränderungen im Laufe der Immunoseneszenz zu einer verschlechterten Antwort auf Infektionen, zu einer erhöhten Anfälligkeit für Krebs sowie zu einem erhöhten Auftreten von Autoimmunerkrankungen beitragen. ${ }^{20}$ In CHF Patienten hat die Verschlechterung von Immunfunktionen eine Auswirkung auf Komorbiditäten und das Outcome. ${ }^{70}$ Darüber hinaus ist die Antikörper-Antwort gegen neue Antigene bei Patienten mit CHF reduziert. ${ }^{80}$ Eine weitere klinische Studie hebt eine regulatorische Funktion der miR-181 in der erworbenen Immunität hervor, indem sie eine Down-Regulation von miR-181a in Patienten mit kindlichem Lupus Erythematodes zeigte. ${ }^{81}$ Lupus Erythematodes ist eine Krankheit, bei der die Produktion autoreaktiver Antikörper zu einer gestörten Immuntoleranz führt. Dies unterstützt die Hypothese, dass die miR-181 Familienmitglieder eine Rolle in der Dysregulation von Immunfunktionen und Veränderungen in der Alterung des Immunsystems spielen könnten, insbesondere im Verlauf von chronischen Erkrankungen, wie z.B. bei der CHF.

77 Yao HC, Liu SQ, Yu K, Zhou M, Wang LX. Interleukin-2 enhances the cytotoxic activity of circulating natural killer cells in patients with chronic heart failure. Heart Vessels. 2009;24(4):2836.

78 Vredevoe DL, Widawski M, Fonarow GC, Hamilton M, Martínez-Maza O, Gage JR. Interleuktin-6 (IL-6) expression and natural killer (NK) cell dysfunction and anergy in heart failure. Am J Cardiol. 2004;93(8):1007-11.

79 Cichocki F, Felices M, McCullar V, et al. Cutting edge: microRNA-181 promotes human NK cell development by regulating notch signaling. J Immunol. 2011;187(12):6171-5.

80 Vardeny O, Moran JJ, Sweitzer NK, Johnson MR, Hayney MS. Decreased T-cell responses to influenza vaccination in patients with heart failure. Pharmacotherapy. 2010;30:10-6.

81 Lashine YA, Seoudi AM, Salah S, Abdelaziz Al. Expression signature of microRNA-181-a reveals its crucial role in the pathogenesis of paediatric systemic lupus erythematosus. Clin Exp Rheumatol. 2011;29:351-7. 
Im Laufe der Immunoseneszenz kommt es zu einem Shift von Lymphopoese in Richtung Myelopoese (Abbildung 17). Im Rahmen dieser Studie zeigte sich eine Assoziation zwischen der miR-181-Expression und Anzeichen einer eingeschränkten Immunfunktion, insbesondere in Form reduzierter zirkulierender BZellen im PB, bei gealterten Menschen und vor allem bei Patienten mit CHF. Dies deckt sich mit den bisherigen Ergebnissen, die einen durch die Immunoseneszenz charakterisierten Rückgang von zirkulierenden B-Zellen im PB sowie einer beeinträchtigten B-Zell-Funktion beschrieben. ${ }^{\text {Fehler! Textmarke nicht definiert.-Fehler! Textmarke }}$ nicht definiert., 82

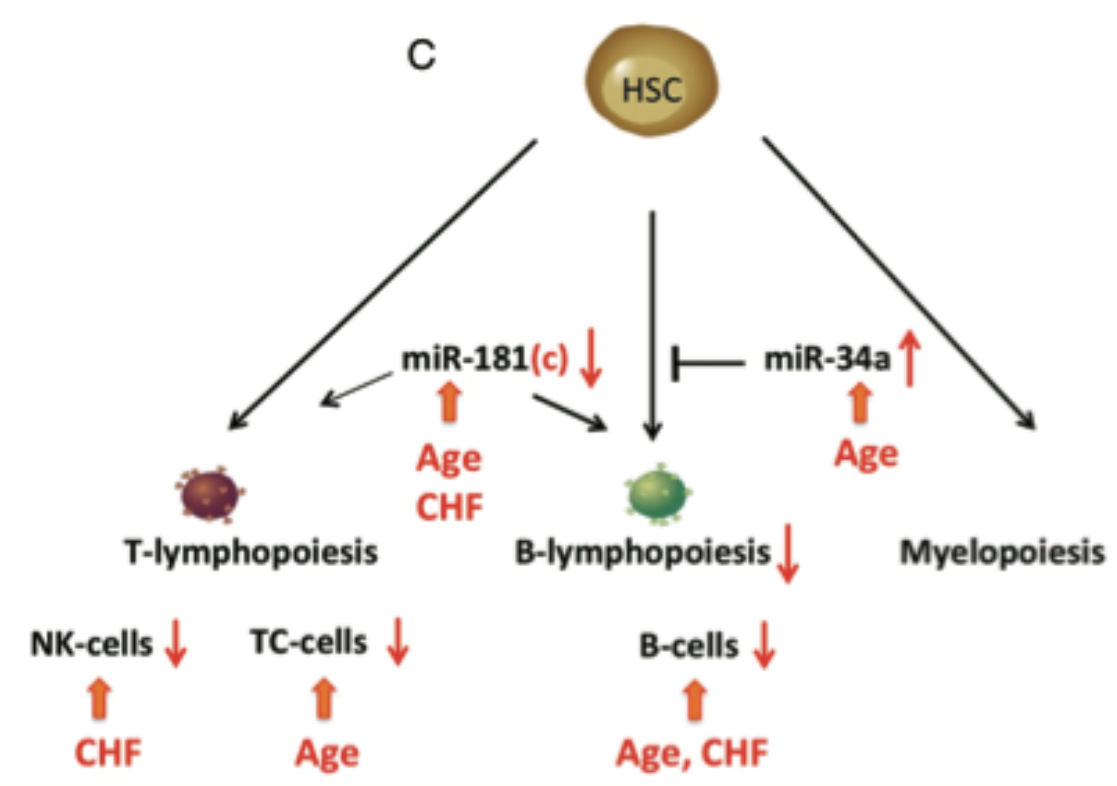

Abbildung 17: hypothetischer Mechanismus, der den Effekt der Alterung und / oder CHF auf das Immunsystem beschreibt

TC-cells: zytotoxische T-Zellen

Aufgrund ihrer spezifischen Expression und breiten Wirkweise können microRNAs potenziell als Biomarker für die Diagnose, den Verlauf sowie als prognostische Faktoren von Erkrankungen fungieren. ${ }^{83}$ Ihre Verwendung als Biomarker wurde bereits im Rahmen unterschiedlicher Krankheiten untersucht. So wurde zum

82 Frasca D, Landin AM, Riley RL, Blomberg BB. Mechanisms for decreased function of B cells in aged mice and humans. J Immunol. 2008;180(5):2741-6.

83 Chen $\mathrm{X}, \mathrm{Ba} \mathrm{Y}, \mathrm{Ma} \mathrm{L}$, et al. Characterization of microRNAs in serum: a novel class of biomarker for diagnosis of cancer and other diseases. Cell. 2008;18:997-1006. 
Beispiel in einer Studie aus den PB-Serum Expressionslevels einer Gruppe aus vier miRNAs in einem Score zusammengefasst, mit Hilfe dessen eine Diskrimination zwischen Patienten mit CHF und gesunden Kontrollen erfolgen kann. Der Score zeigte eine Korrelation mit prognostischen Markern, wie z.B. den BNP Levels. ${ }^{84}$ In unserer Studie konnten wir einen alters- und CHF abhängigen Effekt auf die Expression von miR-181c im peripheren Blut beschreiben. Jedoch sind weitere Studien nötig, um die Rolle von miR-181 in der Immunfunktion aufzuklären, sowie das prädiktive Potential der miR-181c als Biomarker für Immunfunktionen in Patienten mit CHF aufzudecken.

Thai et al zeigten, dass die miR-155 für die Funktion der B- und T-Lymphozyten sowie dendritischen Zellen notwendig ist. ${ }^{61}$ In unserer Studie zeigten wir einen CHF abhängige Reduzierung der Expressionslevels der miR-155. Man könnte daraus schließen, dass die miR-155 auch in der Dysregulation von Immunfunktionen in CHF beteiligt ist. Allerding ließ sich in unseren Untersuchungen kein Zusammenhang zwischen miR-155 und der Anzahl an zirkulierenden B-Zellen nachweisen, wohl aber für die miR-145a und die miR-223. Um die funktionale Relevanz zu identifizieren müssten auch diesbezüglich weitere Studien durchgeführt werden.

Neben der microRNA-Analysen führten wir eine Analyse der Leukozyten Subsets in $\mathrm{y} / \mathrm{h}$, o/h sowie CHF Patienten durch. Unsere Ergebnisse zeigten eine Reduzierung der Anzahl an zirkulierenden B-Zellen in gesunden gealterten Probanden sowie CHF Patienten, was sich mit den bisherigen Ergebnissen über Immunoseneszenz deckt. ${ }^{85}$. Darüber hinaus lieferten wir die ersten Ergebnisse für Unterschiede in der B-Zell Hämostase in Abhängigkeit von der Ätiologie der Herzinsuffizienz. So war die Reduzierung der B-Zellen bei mit ischämisch bedingter Herzinsuffizienz deutlich ausgeprägter im Vergleich zu Herzinsuffizienz auf dem Boden einer Dilatativen Kardiomyopathie. Dieser Unterschied könnte durch die inflammatorische Aktivierung

84 Goren Y, Kushnir M, Zafrir B, Tabak S, Lewis BS, Amir O. Serum levels of microRNAs in patients with heart failure. Eur J Heart Fail. 2012;14:147-54.

85 Paganelli R, Quinti I, Fagiolo U, et al. Changes in circulating cells and immunoglobulin classes and subclasses in a healthy and aged population. Clin Exp Immunol. 1992;90(2):351-4. 
erklärt werden, die bei Patienten mit Arteriosklerose und / oder ischämischer Kardiomyopathie zugrunde liegt.

\subsection{Limitationen der Studie}

Eine Limitation der durchgeführten Studie ist die Variabilität der zugrundeliegenden Proben trotz sorgfältiger Auswahl der Probanden mit klaren Ein- und Ausschlusskriterien.

Eine weitere Limitation der Studie ist, dass die Auswahl der hier untersuchten microRNAs zumeist auf tierexperimentellen Daten beruht. In den letzten Jahren konnte zunehmend gezeigt werden, dass insbesondere das murine und humane Immunsystem deutliche Unterschiede aufweisen, die eine direkte präklinische Translation deutlich einschränkt.

Da im Rahmen dieser Studie die Expressionsanalysen aus PB durchgeführt wurden, stellen Änderungen in der Zusammensetzung des PB im Rahmen von Immunoseneszenz sowie CHF eine Fehlermöglichkeit in der Interpretation der microRNA Messungen dar. Insgesamt jedoch war in der Expression von miR-181c eine klare Diskriminierung der Kohorten zu beobachten. Studien mit Langzeitdaten sind notwendig, um die Frage zu beantworten, ob miR-181c als ein Biomarker für eingeschränkte Immunfunktionen fungieren könnte, insbesondere was den Verlauf der CHF betrifft.

\subsection{Schlussfolgerungen für die Zukunft}

In dieser Studie konnten wir einen alters- und CHF-abhängigen Rückgang der Expression der Mitglieder der miR-181 Familie. Diese könnten in Zukunft als Biomarker fungieren, der die Immunfunktionen der betroffenen Patienten reflektiert. Hier bietet sich vor allem die miR-181c an, die bei Patienten mit CHF im Vergleich zu den anderen Mitgliedern signifikanter reduziert ist als die anderen Mitglieder der miR-181 Familie. 


\section{Zusammenfassung}

Chronische Herzinsuffizienz ist eine der führenden Todesursachen im Rahmen kardiovaskulärer Erkrankungen und ist mit einer hohen Anzahl an Komorbiditäten assoziiert. Unter anderem führt Herzinsuffizienz zu Veränderungen des Immunsystems, welche denen der Immunoseneszenz ähneln. Als einflussreiche Modulatoren ganzer molekularbiologischer Regelkreise sind microRNAs in den letzten Jahren zunehmend in den Fokus gerückt. Diese nicht-kodierenden, kurzen RNA-Einzelstränge können die Genexpression von vielen Zielgenen durch spezifisches Binden der jeweiligen mRNA Transkripte kontrollieren. Aufgrund zum Teil gewebe-, zelltyp- und prozess-spezifischer Expression können microRNAs auch als mögliche Biomarker für spezifische klinische Fragestellungen dienen.

Im Rahmen der vorliegenden Arbeit wurde die Expression von immunmodulatorischen microRNAs im peripheren Blut (PB) von jungen und gealterten gesunden Probanden $(\mathrm{y} / \mathrm{h} \mathrm{bzw} . \mathrm{o} / \mathrm{h}$ ) sowie Patienten mit chronischer Herzinsuffizienz (CHF) untersucht. Dabei wurde ein Bezug auf Immunoseneszenz bzw. die Auswirkung von CHF auf das Immunsystem hergestellt. Im Rahmen dessen wurden Leukozyten-, insbesondere Lymphozyten-Subpopulationen analysiert.

Hierzu wurden Probanden in die drei folgenden Gruppen eingeschlossen: Patienten mit CHF ( $n=18$, durchschnittliches Alter 64 Jahre), alters-korrelierte gesunde Probanden ( $n=13$, durchschnittliches Alter 64 Jahre) sowie junge gesunde Probanden $(n=30$, durchschnittliches Alter 25 Jahre). Neben der Erhebung der klinischen Daten wurde peripheres Blut zur Bestimmung der microRNAExpressionslevels sowie für durchflusszytometrische Analysen der Leukozytenpopulationen gewonnen.

In den Expressionsanalysen konnte eine alters- und herzinsuffizienz-abhängige Dysregulation einzelner microRNAs beobachtet werden. Insbesondere Mitglieder der miR-181-Familie, spezifisch miR-181a und miR-181c, waren im Alter niedriger exprimiert, zudem war die Expression von miR-181c bei Vorliegen einer CHF deutlicher reduziert. Des Weiteren zeigte sich eine altersabhängige erhöhte Expression von miR-34a, wobei das Vorliegen von CHF keine Auswirkung auf die Expression zeigte. Bei den microRNAs miR-146a und miR-223 konnte keine 
signifikante alters- oder CHF-abhängige Regulation nachgewiesen werden. Lediglich zeigte bei der miR-155 zeigte sich eine signifikante Reduktion bei Vorliegen einer CHF im Vergleich o/h Probanden.

In Hinblick auf die Leukozytenpopulationen im peripheren Blut wiesen Patienten mit CHF höhere Zahlen an Leukozyten auf, alle miR-181 Mitglieder zeigten hierbei eine inverse Korrelation. Dagegen stellte sich in Hinblick auf die Zusammensetzung der Leukozyten-Subpopulationen eine Reduktion der Lymphozytenfraktion im Alter dar, besonders bei Patienten mit CHF. Insbesondere zeigte sich eine altersabhängige Abnahme der B-Lymphozytenpopulation, wobei auch hier das Vorliegen einer CHF diesen Effekt verstärkte. Die Expression miR-181a und miR-181c sowie miR-146a und miR-223 korrelierte positiv mit dem Anteil der B-Lymphozyten. Innerhalb der BZellen zeigte sich eine alters- und CHF-abhängige Reduktion der naïven B-Zellen, welche positiv mit der Expression von miR-181c, miR-146a und miR-223 korrelierte. Die beobachteten Veränderungen der B-Zell-Subpopulationen zeigten sich insbesondere bei CHF Patienten mit ischämischer Ursache im Vergleich zur dilatativen Kardiomyopathie.

Bei den untersuchten T-Lymphozyten-Subpopulationen zeigte sich eine altersabhängiger Abfall bei den zytotoxischen T-Zellen. Das Vorliegen einer CHF verstärkte diesen Effekt. Die beobachteten Veränderungen der T-Zell-Subpopulation korrelierten nicht mit der Expression der untersuchten microRNAs.

Im Gegensatz zu den lymphoiden Subpopulationen zeigte sich ein Anstieg der neutrophilen Granulozyten und der Monozyten im Alter, es stellte sich jeweils eine negative Korrelation mit der Expression von miR-181 Transkripten sowie miR-155, miR-146a und miR-223 dar.

Zusammenfassend zeigten sich signifikant erniedrigte Expressionslevels von miR$181 \mathrm{c}$ im Alter, was mit Immunoseneszenz-bedingten Veränderungen des peripheren Bluts einherging. Diese Veränderungen zeigten sich zusätzlich verstärkt bei Patienten mit CHF. Zukünftig könnten miR-181c Expressionslevel in peripherem Blut als Biomarker für die Immunfunktionen bei CHF Patienten dienen und in Hinblick auf eine mögliche prospektive Information evaluiert werden. 


\section{Abstract}

Chronic heart failure is one of the main causes of death as part of cardiovascular diseases and its associated with many comorbidities. Amongst other chronic heart failure leads to changes in the immune system which may be related the immunosenescence. MicroRNAs are known as important regulators in different molecular biological control loops. These small, non-coding RNA molecules can control gene expression through their targeted binding to specific mRNAs. Because of their tissue-, cell-type and context-dependent expression microRNAs do have the ability to act as biomarkers for pathophysiological processes.

We analyzed the expression levels of immunomodulating microRNAs in the peripheral blood (PB) of young and healthy controls, patients with chronic heart failure as well as age-matched healthy controls. To determine a potential impact on the immune system, analyzed leucocyte- and especially lymphocyte subsets.

The study subjects where included in three different groups: Patients with CHF $(n=18$, average age 64 years), age-matched healthy controls $(n=13$, average age 64 years) and young and healthy controls ( $n=30$, average age 25 years). We collected clinical data and furthermore collected PB to determine microRNA expression levels as well as for further flow cytometric analysis of leucocyte populations.

We detected an age- and CHF-dependent dysregulation of some microRNAs in our expression analysis. Comparing young and old healthy individuals, members of miR181 family showed a reduced expression with increasing age especially for miR181a and c. Moreover, miR-181c showed an even more noticeable decrease in case of CHF. Furthermore, we showed an age-dependent increase of miR-34a expression, here, CHF did not affect the expression levels. The other microRNAs, namely miR-146a and miR-223 did not show a significant age- or CHF-dependent regulation. Only miR-155 showed significantly decreased expression levels in CHF patients compared to o/h controls.

Regarding the leucocyte-populations in the peripheral blood CHF patients showed an increase number of leucocytes, here, all miR-181 family members showed an inversed correlation. Focusing on the leucocyte subsets, we observed a decrease in the lymphocyte fraction in age, especially in patients with CHF. Specifically, the 
population of B-Lymphocytes showed an age-dependent decrease and here also, the presence of CHF emphasized that effect. Expression levels of miR-181a and miR-181c as well as miR-146a and miR-223 showed a positive correlation with the fraction of B-lymphocytes. We further observed an age- and CHF-dependent decrease of naïve B-cells which positively correlated with expression levels of miR181c, miR-146a and miR-223. Those changes in the subsets of B-cells where more pronounced in CHF patients with ischemic heart disease compared with dilatative cardiomyopathy.

Regarding the T-lymphocyte subsets our studies showed an age-dependent decrease in cytotoxic T-cells. That effect was even pronounced in patients with CHF. Changes within the T-cell subsets did not correlate with expression levels of the analyzed microRNAs.

In contrast to the lymphocyte subsets we noticed an increase of neutrophils and monocytes with increasing age showing a negative correlation of the miR-181 family members as well as miR-155, miR-146a and miR-223.

In conclusion, our study showed an age-dependent decrease of miR-181c expression in PB and correlations with changes during immunosenescence. Those changes where more pronounced in patients suffering CHF. In future, microRNA181c expression levels in peripheral blood could function as biomarkers for the immune status in CHF patients and furthermore could be used for prospective information. 


\section{Literaturverzeichnis}

1. Walford RL. The immunologic theory of aging. Gerontologist. 1969;4:195-7.

2. Weisskopf $D$, Weinberger B, Grubeck-Loebenstein B. The aging of the immune system. Transpl Int. 2009;22:1041-50.

3. Globerson A, Effros RB. Ageing of lymphocytes and lymphocytes in the aged. Immunol Today. 2000;10:515-21.

4. Plackett TP, Boehmer ED, Faunce DE, Kovacs EJ. Aging and innate immune cells. J Leukoc Biol. 2004;76:291-9.

5. Franceschi $\mathrm{C}$, Bonafe $\mathrm{M}$, Valensin $\mathrm{S}$. Human immunosenescence: the prevailing of innate immunity, the failing of clonotypic immunity, and the filling of immunological space. Vaccine. 2000; 18:1717-20.

6. Seita J, Weissman IL. Hematopoietic Stem Cell: self-renewal versus differentiation. Wiley Interdiscip Rev Syst Biol. Med. 2010;2(6):640-53.

7. Orkin SH, Zon LI: Hematopoiesis: an evolving paradigm for stem cell biology. Cell. 2008;132(4):631-44.

8. Wikipedia. https://commpns. wikiedia.org/w/index.php?curid=15411966. Mai, 05, 2020.

9. Mason D, André P, Bensussan A. CD antigens 2002. Blood. 2002;15;99:387780.

10. Linton PJ, Dorshkind K. Age-related changes in lymphocyte development and function. Nat Immunol. 2004;5:133-39.

11. Geiger H, Rudolph KL. Aging in the lympho-hematopoietic stem cell compartment. Trends Immunol. 2009;30:360-5.

12. Johnson KM, Owen K, Witte PL. Aging and developmental transitions in the $B$ cell lineage. Int Immunol. 2002;14(11):1313-23.

13. Peters T. Immunosenescence. Current status and molecular mechanisms. Hautarzt. 2011; 62(8):598-606.

14. Matteo B, Calogero C, Giuseppina CR. From lymphopoiesis to plasma cells differentiation, the age-related modifications of $\mathrm{B}$ cell compartment are influenced by „inflamm-ageing“. Ageing Res Rev. 2017;36:125-36. 
15. Wenjuan T, Sudha R. Mechanisms underlying T cell immunosenescence: aging and Cytomegalovirus infection. Front Microbiol. 2016;7:2111.

16. Fukushima Y, Minato N, Massakazu H. The impact of senescence-associated T cells on immunosenescence and age-related disorders. Inflamm Regen. 2018;38:24.

17. Miller RA. The aging immune system: primer and prospectus. Science. 1996;273:70-4.

18. Pawelec G, Solana R, Remarque E, Mariani E. Impact of aging on innate immunity. J Leukoc Biol. 1998;64:703-12.

19. Pawelec G. Immunosenescence: impact in the young as well as in the old? Mech Ageing Dev. 1999;108:1-7.

20. Ademokun A, Wu YC, Dunn-Walters D. The ageing B cell population: composition and function. Biogerontology. 2010;11:125-37.

21. Lakatta EG. Age-associated cardiovascular changes in health: impact on cardiovascular disease in older persons. Heart Fail Rev. 2002;7(1):29-49.

22. North BJ, Sinclair DA. The intersection between aging and cardiovascular disease. Circ Res. 2012;110:1097-108.

23. Fox KF, Cowie MR, Wood DA, et al. Coronary artery disease as the cause of incident heart failure in the population. Eur Heart J. 2001;22(3):228-35.

24. Dickstein K, Cohen-Solal A, Filippatos G, et al. ESC Guidelines for the diagnosis and treatment of acute and chronic heart failure 2008: The task force for the diagnosis and treatment of acute and chronic heart failure 2008 of the European Society of Cardiology. developed in collaboration with the Heart Failure Association of the ESC (HFA) and endorsed by the European Society of Intensive Care Medicine (ESICM). Eur Heart J. 2008;29(19):2388-442.

25. Schultheiss HP, Fairweather D, Caforio ALP, et al. Dilated cardiomyopathy. Nat Rev Dis Primers. 2019;9;5(1):32

26. Reichart D, Magnussen C, Zeller T, Blankenberg S. Dilated cardiomyopathy: from epidemiologic to genetic phenotypes. J Int Med. 2019;286/4:362-72.

27. Seeger T, Chen C, Karakikes I, Wu JC. Cardiac remodeling and regeneration. Cardiac Electrophysiology: From Cell to Bedside. 7th ed., 2018. 
28. Erdmann. Klinische Kardiologie. Krankheiten des Herzens, des Kreislaufs und der herznahen Gefäße. 8. überarbeitete Aufl. Springer Verlag, Heidelberg 2011.

29. Genth-Zotz S, von Haehling S, Blankenberg S. Immunactivation in chronic heart failure: inflammatory mediators. Z Kardiol. 2004;93:24-30.

30. Bui AL, Horwich TB, Fonarow GC. Epidemiology and risk profile of heart failure. Nat Rev Cardiol. 2011;8:30-41.

31. Mosterd A, Hoes AW. Clinical Epidemiology of heart failure. Heart. 2007;93:1137-1146.

32. Leitlinien. https://www.leitlinien.de/nvl/html/nvl-chronische-herzinsuffizienz/3auflage/kapitel-2. Januar 2019.

33. Herold G. Innere Medizin. Eine vorlesungsorientierte Darstellung. 2018.

34. Kannel WB, Ho K, Thom T. Changing epidemiological features of cardiac failure. Eur Heart J. 1994;72:3-9.

35. Akosah KO, Moncher K, Schaper A, Havlik P, Devine S. Chronic heart failure in the community: missed diagnosis and missed opportunities. J Card Fail. 2001;7:232-8.

36. von Haehling S, Schefold JC, Jankowska E, et al. Leukocyte redistribution: effects of beta blockers in patients with chronic heart failure. PLoS One. 2009;4:e6411.

37. Anker SD, von Haehling S. Inflammatory mediators in chronic heart failure: an overview. Heart. 2004;90:464-70.

38. Rauchhaus M, Doehner W, Francis DP, Davos C, Kemp M, et al. Plasma cytokine parameters and mortality in patients with chronic heart failure. Circulation. 2000;19;102:3060-7.

39. Deswal A, Petersen NJ, Feldman AM, Young JB, White BG, et al. Cytokines and cytokine receptors in advanced heart failure: an analysis of the cytokine database from the Vesnarinone trial (VEST). Circulation. 2001;103:2055-9.

40. Mari, D, Di Berardino, F, Cugno, M. Chronic heart failure and the immune system. Clinic Rev Allerg Immunol. 2002;23:325-40. 
41. Anker SD, Egerer KR, Volk HD, Kox WJ, Poole-Wilson PA, Coats AJ. Elevated soluble CD14 receptors and altered cytokines in chronic heart failure. Am J Cardiol. 1994;49:1426-30.

42. Niebauer J, Volk HD, Kemp M, Dominguez M, et al. Endotoxin and immune activation in chronic heart failure. A prospective cohort study. Lancet. 1999;353:1838-1842.

43. Habib FM, Springall DR, Davies GJ, Oakley CM, Yacoub MH, Polak J. Tumor necrosis factor and inducible nitric oxide synthase in dilated cardiomyopathy. Lancet. 1996;347:1151-5.

44. Scannell G, Waxman K, Kaml GJ,et al. Hypoxia induces a human macrophage cell line to release tumor necrosis factor- $\alpha$ and its soluble receptors in vitro. $J$ Surg Reg. 1993;54:281-5.

45. Maisel AS, Knowloton KU, Fowler $P$, et al. Adrenergic control of circulating lymphocyte subpopulations. Effects of congestive heart failure, dynamic exercise, and terbutaline treatment. J Clin Invest. 1990;85:462-7.

46. Nunez J, Nunez E, Minana G, et al. Effectiveness of the relative lymphocyte count to predict one-year mortality in patients with acute heart failure. $A m \mathrm{~J}$ Cardiol. 2011;107:1034-9.

47. Acanfora D, Gheorghiade M, Trojano L, et al. Relative lymphocyte count: a prognostic indicator of mortality in elderly patients with congestive heart failure. Am Heart J. 2001;142:167-73.

48. Bartel DP. MicroRNAs: target recognition and regulatory functions. Cell. 2009;136(2):215-33.

49. Lee RC, Feinbaum RL, Ambros V. The C. elegans heterochronic gene lin-4 encodes small RNAs with antisense complementarity to lin-14. Cell. 1993;75(5):843-54.

50. Lagos-Quintana M, Rauhut R, Lendeckel W, Tuschl T. Identification of novel genes coding for small expressed RNAs. Science. 2001;294:853-58.

51. Bonauer A. Die Bedeutung von microRNAs für die Funktion von Endothelzellen [Dissertation].Frankfurt, Johann Wolfgang Goethe-Universität; 2008. 
52. Lee $\mathrm{Y}$, Ahn $\mathrm{C}$, Han J, et al. The nuclear RNase III Drosha initiates microRNA processing. Nature. 2003;425:415-9.

53. Lund E, Guttlinger S, Calado A, Dahlberg JE, Kutay U. Nuclear export of microRNA precursors. Science. 2004;303:95-8.

54. Bartel DP. MicroRNAs: genomics, biogenesis, mechanism, and function. Cell. 2004;116:281-97.

55. Hammond SM, Boettcher S, Caudy AA, Kobayashi R, Hannon GJ. Argonaute2, a link between genetic and biochemical analyses of RNA. Science. 2001;293;146-50.

56. Meister G, Tuschl T. Mechanisms of gene silencing by double-stranded RNA. Nature. 2004;431:343-9.

57. Wang LD, Wagers AJ. Dynamic niches in the origination and differentiation of haematopoietic stem cell. Nat Rev Mol Cell Biol. 2011;12(10):643-55.

58. Chen CZ, Li L, Lodish HF, Bartel DP. MicroRNAs modulate hematopoietic lineage differentiation. Science. 2004;303:83-6.

59. Rao DS, O'Connell RM, Chaudhuri AA, Garcia-Flores y, Geiger TL, Baltimore D. MicroRNA-34a pertubs B lymphocyte development by repressing the forkhead box transcription factor Foxp1. Immunity. 2010;33:48-59.

60. Georgantas RW 3rd, Hildreth R, Morisot S, et al. CD34+ hematopoietic stemprogenitor cell microRNA expression and function: a circuit diagram of differentiation control. Pro Natl Acad Sci U S A. 2007;104:2750-5.

61. Thai TH, Calado DP, Casola $S$, et al. Regulation of the germinal center response by microRNA-155. Science. 2007;316:604-8.

62. Johnnidis JB, Harris $\mathrm{MH}$, Wheeler RT, et al. Regulation of progenitor cell proliferation and granulocyte function by microRNA-223. Nature. 2008;451:1125-9.

63. De Lencastre A, Pincus Z, Zhou K, Kato M, Lee SS, Slack FJ. MicroRNAs both promote and antagonize longevity in C. elegans. Curr Biol. 2010;20:2159-68.

64. Ito T, Yagi S, Yamakuchi M. MicroRNA-34a regulation of endothelial senescence. Biochem Biophys Res Commun. 2010;398:735-40. 
65. Dimmeler S, Nicotera P. MicroRNAs in age-related diseases. EMBO Mol Med. 2013;5:180-90.

66. Kato $M$, Chen X, Inukai $S$, Zhao $H$, Slack FJ. Age-associated change in expression of small noncoding RNAs, including microRNAs, in C. elegans. RNA. 2011;17:1804-1820.

67. Ibanze-Ventoso C, Yang M, Guo S, Robins H, Padgett RW, Driscoll M. Modulated microRNA expression during adult lifespan in Caenorhabditis Elegans. Aging Cell. 2006;5:235-46.

68. Ramkissoon SH, Mainwaring LA, Ogasawara Y, et al. Hematopoietic-specific microRNA expression in human cells. Leuk Res. 2006;30:643-7.

69. Merkerova M, Belickova M, Bruchova $\mathrm{H}$. Differential expression of microRNAs in hematopoietic cell lineages. Eur J Haematol. 2008;81:304-10.

70. Fildes JE, Shaw SM, Yonan N, Williams SG. The immune system and chronic heart failure. Is the heart in control? J Am Coll Cardiol. 2009;53(12):1013-20.

71. Yang J, Chen D, He Y, et al. MiR-34 modulates Caenorhabditis elegans lifespan via repressing the autophagy gene atg9. Age (Dordr). 2013;35(1):11-22.

72. Li N, Bates DJ, An J, Terry DA, Wang E. Up-regulation of key microRNAs, and inverse down-regulation of their predicted oxidative phosphorylation target genes, during aging in mouse brain. Neurobiol Aging. 2011;32:944-55.

73. Xu Q, Seeger FH, Castillo J, et al. Micro-RNA-34a contributes to the impaired function of bone marrow-derived mononuclear cells from patients with cardiovascular disease. J Am Coll Cardiol. 2012;59:2107-17.

74. Liu G, Min H, Yue S, Chen CZ. Pre-MiRNA loop nucleotides control the distinct activities of mir-181a-1 and mir-181c in early T cell development. PLoS One 2008; 2008;3:e3592.

75. Li QJ, Chau J, Ebert PJ, et al. miR-18 1a is an intrinsic modulator of $\mathrm{T}$ cell sensitivity and selection. Cell. 2007; 129:147-61.

76. Li G, Yu M, Lee WW, et al. Decline in miR-181a expression with age impairs $T$ cell receptor sensitivity by increasing DUSP6 activity. Nat Med. 2012;18(10):1518-24. 
77. Yao HC, Liu SQ, Yu K, Zhou M, Wang LX. Interleukin-2 enhances the cytotoxic activity of circulating natural killer cells in patients with chronic heart failure. Heart Vessels. 2009;24(4):283-6.

78. Vredevoe DL, Widawski M, Fonarow GC, Hamilton M, Martínez-Maza O, Gage JR. Interleuktin-6 (IL-6) expression and natural killer (NK) cell dysfunction and anergy in heart failure. Am J Cardiol. 2004;93(8):1007-11.

79. Cichocki F, Felices M, McCullar V, et al. Cutting edge: microRNA-181 promotes human NK cell development by regulating notch signaling. J Immunol. 2011;187(12):6171-5.

80. Vardeny O, Moran JJ, Sweitzer NK, Johnson MR, Hayney MS. Decreased T-cell responses to influenza vaccination in patients with heart failure. Pharmacotherapy. 2010;30:10-6.

81. Lashine YA, Seoudi AM, Salah S, Abdelaziz Al. Expression signature of microRNA-181-a reveals its crucial role in the pathogenesis of paediatric systemic lupus erythematosus. Clin Exp Rheumatol. 2011;29:351-7.

82. Frasca D, Landin AM, Riley RL, Blomberg BB. Mechanisms for decreased function of B cells in aged mice and humans. J Immunol. 2008;180(5):2741-6.

83. Chen $\mathrm{X}, \mathrm{Ba} \mathrm{Y}, \mathrm{Ma} \mathrm{L}$, et al. Characterization of microRNAs in serum: a novel class of biomarker for diagnosis of cancer and other diseases. Cell. 2008;18:997-1006.

84. Goren Y, Kushnir M, Zafrir B, Tabak S, Lewis BS, Amir O. Serum levels of microRNAs in patients with heart failure. Eur $J$ Heart Fail. 2012;14:147-54.

85. Paganelli R, Quinti I, Fagiolo $U$, et al. Changes in circulating cells and immunoglobulin classes and subclasses in a healthy and aged population. Clin Exp Immunol. 1992;90(2):351-4. 
Fatima Bach, geb. Haffez

geboren am 06.01.1989 in Lahore

Eltern: Abduhl Haffez ${ }^{\dagger}$, Salma Haffez, geb. Iqbal

\section{Schulischer und akademischer Werdegang}

$2007-2013$

$09 / 2009$

$11 / 2013$

$03 / 2012-03 / 2013$

$11 / 2010-11 / 2011$

2007

1995

Studium der Humanmedizin, Universität Frankfurt a.M.

1. Abschnitt der Ärztlichen Prüfung

2. Abschnitt der Ärztlichen Prüfung

Studium der Wirtschaftswissenschaften, Universität Frankfurt a.M.

Stipendiatin bei Endothelial Signalling and Vascular

Repair (Sonderforschungsbereich 834)

Abitur in Neu-Isenburg

Einschulung in Neu-lsenburg

Beruflicher Werdegang

09/2020

Seit 06/2019

$01 / 2019-06 / 2019$

$12 / 2015-12 / 2018$

$10 / 2017-03 / 2018$

$02 / 2014-11 / 2015$

$08 / 2012-08 / 2013$
Fachärztin für Allgemeine Chirurgie

Assistenzärztin in der Klinik für Wirbelsäulenchirurgie (Prof. Dr. M. Rauschmann), Sana Klinikum Offenbach Assistenzärztin in der Klinik für Unfallchirurgie (Prof. U. Horas), Krankenhaus Bad Soden Assistenzärztin in der Klinik für Allgemein- und Viszeralchirurgie (Prof. Dr. D. Lorenz sowie Dr. M. Pauthner), Sana Klinikum Offenbach Rotationsassistentin in der Klinik für Allgemeinchirurgie (Dr. L. Brinkmann), St. Vinzenz Krankenhaus Hanau Assistenzärztin in der Anästhesiologie (Dr. R. Tessmann sowie Prof. Dr. B. Nohé), Sana Klinikum Offenbach Praktisches Jahr, Nordwest-Krankenhaus Frankfurt 


$\begin{array}{cl}\begin{array}{c}\text { Famulaturen } \\ 05 / 2012\end{array} & \text { Unfallchirurgie und Orthopädie an der BG Unfallklink } \\ & \text { Frankfurt/Main (Prof. Dr. R. Hoffmann) } \\ 07 / 2011 & \text { Anästhesie in Aklepios Klinik Langen } \\ & \text { (Prof. Dr. H.-B. Hopf) } \\ 01 / 2011 & \text { Kardiologie in der Universitätsklinik Frankfurt/Main } \\ & \text { (Prof. Dr. A.M. Zeiher) } \\ 07 / 2010 & \text { Neurochirurgie in der Universitätsklinik Frankfurt/Main } \\ & \text { (Prof. Dr. V. Seifert) }\end{array}$




\section{Schriftliche Erklärung}

Ich erkläre ehrenwörtlich, dass ich die dem Fachbereich Medizin der Johann Wolfgang Goethe-Universität Frankfurt am Main zur Promotionsprüfung eingereichte Dissertation mit dem Titel

Evaluierung immunmodulatorischer microRNAs im Rahmen von Immunoseneszenz und chronischer Herzinsuffizienz

in dem Institut für Kardiovaskuläre Regeneration unter Betreuung und Anleitung Prof. Dr. Stefanie Dimmeler mit Unterstützung durch Dr. Timon Seeger ohne sonstige Hilfe selbst durchgeführt und bei der Abfassung der Arbeit keine anderen als die in der Dissertation angeführten Hilfsmittel benutzt habe. Darüber hinaus versichere ich, nicht die Hilfe einer kommerziellen Promotionsvermittlung in Anspruch genommen zu haben.

Ich habe bisher an keiner in- oder ausländischen Universität ein Gesuch um Zulassung zur Promotion eingereicht ${ }^{*}$. Die vorliegende Arbeit wurde bisher nicht als Dissertation eingereicht.

Vorliegende Ergebnisse der Arbeit wurden (oder werden) in folgendem Publikationsorgan veröffentlicht:

Seeger, T, Haffez, F, Fischer, A, Koehl, U, Leistner, DM, Seeger, FH, Boon, RA, Zeiher, AM, Dimmeler, S. Immunosenescence-associated microRNAs in age and heart failure, European Journal of Heart Failure, 385-93, 2013. 